\title{
Sex Differences in Behavioral and Brainstem Transcriptomic Neuroadaptations following Neonatal Opioid Exposure in Outbred Mice
}

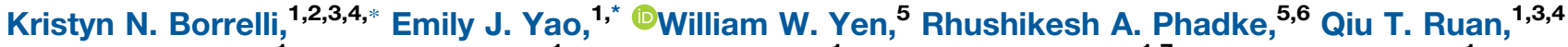 \\ Melanie M. Chen, ${ }^{1}$ Julia C. Kelliher, ${ }^{1}$ Carly R. Langan, ${ }^{1}$ Julia L. Scotellaro, ${ }^{1,7}$ Richard K. Babbs, ${ }^{1}$ \\ Jacob C. Beierle, ${ }^{1,3,4}$ CRyan W. Logan, ${ }^{8,9}$ William Evan Johnson, ${ }^{10}$ Elisha M. Wachman, ${ }^{11}$ \\ Alberto Cruz-Martín, ${ }^{5}$ and ${ }^{-}$Camron D. Bryant ${ }^{1}$
}

\section{https://doi.org/10.1523/ENEURO.0143-21.2021}

${ }^{1}$ Laboratory of Addiction Genetics, Departments of Pharmacology and Experimental Therapeutics and Psychiatry, Boston University School of Medicine, Boston, Massachusetts 02118, ${ }^{2}$ Graduate Program for Neuroscience, Boston University, Boston, Massachusetts 02118, ${ }^{3}$ Transformative Training Program in Addiction Science, Boston University, Boston, Massachusetts 02118, ${ }^{4}$ NIGMS Training Program in Biomolecular Pharmacology, Boston University School of Medicine, Boston, Massachusetts 02118, ${ }^{5}$ Neurobiology Section, Department of Biology, Boston University, Boston, Massachusetts 02215, ${ }^{6}$ Molecular Biology, Cell Biology, and Biochemistry (MCBB), Boston University, Boston, Massachusetts 02215, ${ }^{7}$ Undergraduate Research Opportunity Program, Boston University, Boston, Massachusetts 02118, ${ }^{8}$ Laboratory of Sleep, Rhythms, and Addiction, Department of Pharmacology and Experimental Therapeutics, Boston University School of Medicine, Boston, Massachusetts $02118,{ }^{9}$ Center for Systems Neurogenetics of Addiction, The Jackson Laboratory, Bar Harbor, Maine 04609, ${ }^{10}$ Department of Medicine, Computational Biomedicine, Boston University School of Medicine, Boston, Massachusetts 02118, and ${ }^{11}$ Department of Pediatrics, Boston University School of Medicine, Boston Medical Center, Boston, Massachusetts 02118

\begin{abstract}
The opioid epidemic led to an increase in the number of neonatal opioid withdrawal syndrome (NOWS) cases in infants born to opioid-dependent mothers. Hallmark features of NOWS include weight loss, severe irritability, respiratory problems, and sleep fragmentation. Mouse models provide an opportunity to identify brain mechanisms that contribute to NOWS. Neonatal outbred Swiss Webster Cartworth Farms White (CFW) mice were administered morphine (15 mg/kg, s.c.) twice daily from postnatal day 1 (P1) to $\mathrm{P} 14$, an approximation of the third trimester of human gestation. Female and male mice underwent behavioral testing on P7 and P14 to determine the impact of opioid exposure on anxiety and pain sensitivity. Ultrasonic vocalizations (USVs) and daily body weights were also recorded. Brainstems containing pons and medulla were collected during morphine withdrawal on P14 for RNA sequencing. Morphine induced weight loss from P2 to P14, which persisted during adolescence (P21) and adulthood (P50). USVs markedly increased at P7 in females, emerging earlier than males. On P7 and P14, both morphine-exposed female and male mice displayed hyperalgesia on the hot plate and tail-flick assays, with females showing greater hyperalgesia than males. Morphine-exposed mice exhibited increased anxiety-like behavior in the open-field arena on P21. Transcriptome analysis of the
\end{abstract}

\section{Significance Statement}

Neonatal opioid withdrawal syndrome (NOWS) is a poorly understood condition that has both a genetic and environmental component and is thought to be mechanistically distinct from opioid withdrawal in adults. The development of murine models for measuring neurobehavioral responses is critical for informing the neurobiological adaptations underlying NOWS. Using outbred mice that more closely model human genetic variation, we discovered several sex differences in behavioral timing and severity of NOWS model behaviors as well as transcriptomic adaptations in brain tissue that together suggest distinct mechanisms and sexspecific therapeutics for reversing withdrawal symptoms and restoring brain function. 
brainstem, an area implicated in opioid withdrawal and NOWS, identified pathways enriched for noradrenergic signaling in females and males. We also found sex-specific pathways related to mitochondrial function and neurodevelopment in females and circadian entrainment in males. Sex-specific transcriptomic neuroadaptations implicate unique neurobiological mechanisms underlying NOWS-like behaviors.

Key words: neonatal abstinence syndrome; neonatal opioid withdrawal syndrome; opiate; opioid dependence; perinatal; rodents

\section{Introduction}

The United States is in the midst of an opioid use disorder (OUD) epidemic. A recent report by the Centers for Disease Control and Prevention indicated a record 93,000 opioid-related deaths in 2020-a 29\% increase from 2019 (https://www.cdc.gov). The OUD epidemic has been accompanied by a surge in infants exposed to opioids in utero (Jansson and Patrick, 2019) and a rise in rates of neonatal opioid withdrawal syndrome (NOWS; Milliren et al., 2018). NOWS is characterized by low birth weight, reduced weight gain, severe irritability, sleep fragmentation and restlessness, hypertonia, elevated pain sensitivity, and high-pitched cry, among other symptoms (Sutter et al., 2014). The current standard of treatment for NOWS includes tapered dosing of opioids over days or weeks, and other interventions that promote mother-infant bonding (Wachman et al., 2018; Ryan et al., 2019). Current treatments for NOWS primarily attenuate withdrawal severity for the infant and are believed to mitigate the potential long-term impact on mood, cognition, and pain. Further understanding of the impact of opioids on development is critical for the discovery, design, and implementation of new treatments and interventions for NOWS.

Several animal models for NOWS have been developed (Fodor et al., 2014; Chen et al., 2015; Byrnes and Vassoler, 2018), differing in time of exposure (i.e., prenatally, postnatally, or both), specific opioid (morphine, heroin, methadone, oxycodone, and/or buprenorphine), and dosing regimen (e.g., injections, pellets, mini-pumps; Byrnes and

Received March 31, 2021; accepted August 25, 2021; First published September 3, 2021.

The authors declare no competing financial interests.

Author contributions: A.C.-M. and C.D.B. designed research; K.N.B., E.J.Y., M.M.C., J.C.K., C.R.L., J.L.S., R.K.B., J.C.B., E.M.W., A.C.-M., and C.D.B. performed research; K.N.B., E.J.Y., W.W.Y., R.A.P., Q.T.R., M.M.C., J.C.K., J.L.S., R.K.B., J.C.B., R.W.L., W.E.J., E.M.W., A.C.-M., and C.D.B. analyzed data; K.N.B., E.J.Y., W.W.Y., R.W.L., E.M.W., A.C.-M., and C.D.B. wrote the paper.

This research was supported by the Spivack Center for Clinical and Translational Neuroscience; National Institute on Drug Abuse Grants U01-DA050243 and R01-DA-039168 (C.D.B.); National Heart, Lung, and Blood Institute Grant R01-150432 (R.W.L); Eunice Kennedy Shriver National Institute of Child Health and Human Development Grant R01-HD-096798 (E.W.); National Alliance for Research on Schizophrenia and Depression Young Investigator Grant 27202 (A.C-M.); and Boston University's Undergraduate Research Opportunities Program (J.L.S.)

${ }^{*}$ K.N.B. and E.J.Y. contributed equally to this work.

Correspondence should be addressed to Camron D. Bryant at camron@ bu.edu.

https://doi.org/10.1523/ENEURO.0143-21.2021

Copyright @ 2021 Borrelli et al.

This is an open-access article distributed under the terms of the Creative Commons Attribution 4.0 International license, which permits unrestricted use, distribution and reproduction in any medium provided that the original work is properly attributed.
Vassoler, 2018; Robinson et al., 2020; Minakova et al., 2021). The physiological and behavioral consequences of opioids on development depends on the timing, duration, and route of drug administration (Fodor et al., 2014; Byrnes and Vassoler, 2018). In rodents, the period between postnatal day 1 (P1) through $\mathrm{P} 14$ is an approximation of the third trimester of human gestation (Barr et al., 2011), characterized by rapid, extensive synaptogenesis and myelination in the brain (Semple et al., 2013). For example, morphine administration between P1 and P14 (Robinson et al., 2020) in mice induced neurodevelopmental delays and effects on behaviors later during adolescence and adulthood, including marble burying and morphine locomotor sensitization behaviors (Robinson et al., 2020). Early neonatal opioid exposure in rodents has the following several key advantages: (1) opioid exposure during third trimester is associated with a higher risk for NOWS in human neonates (Desai et al., 2015), providing strong translational relevance; (2) neonatal exposure during the third trimester equivalent is sufficient to produce symptoms of withdrawal in mice and rats (Jones and Barr, 1995, 2001; McPhie and Barr, 2009; Robinson et al., 2020); (3) postnatal delivery of opioids enables accurate dosing to each pup; (4) avoiding maternal opioid exposure reduces the potential variance introduced by opioid-dependent alterations in maternal caretaking behaviors; and (5) the short-term and long-term effects of opioids on the brain and behavior can be assigned to a specific developmental period using discrete, timed administration of opioids.

Given these advantages, in the present study, we used an administration regimen similar to that previously described (Robinson et al., 2020) to further investigate the consequences of neonatal opioid exposure in mouse model of NOWS, including ultrasonic vocalizations (USVs), anxiety, and pain behaviors. To gain insight into the neurobiological adaptations related to NOWS, we also investigated the transcriptional alterations in the brainstem (medulla plus pons), a region of the brain implicated in neonatal opioid withdrawal (Jones and Barr, 2001; Maeda et al., 2002; McPhie and Barr, 2009) and hyperalgesia (Bederson et al., 1990; Kaplan and Fields, 1991; Vanderah et al., 2001; Ossipov et al., 2005; Xie et al., 2005; Vera-Portocarrero et al., 2011). We conducted our studies in outbred Cartworth Farms White (CFW) mice (Swiss Webster; both males and females) because of their greater genetic heterozygosity and increased number of historical recombination events compared with inbred strains and short-term (e.g., F2) intercrosses between them. These characteristics more closely model the complex genetic architecture of the human genome (Tuttle et al., 2018) and can be leveraged in future studies to conduct high-resolution genetic mapping of NOWS-related phenotypes (Gonzales and Palmer, 2014; Parker et al., 2016; Gonzales et al., 2018). 


\section{Materials and Methods}

\section{Mice}

All experiments in mice were conducted in accordance with the National Institutes of Health Guide for the Care and Use of Laboratory Animals and were approved by the Institutional Animal Care and Use Committee. Outbred CFW mice (Swiss Webster) were purchased from Charles River Laboratory at 8 weeks of age. Breeders were paired after 1 week of habituation to the vivarium. Each breeder mouse was from a different litter, thus minimizing relatedness within a breeder pair (Parker et al., 2016). Laboratory chow (Teklad 18\% Protein Diet, Envigo) and tap water were available ad libitum. Breeder cages were provided with nestlets. A maximum of three sequential litters per breeder were used in the study. Mice were maintained on a $12 \mathrm{~h}$ light/dark cycle (lights on, 6:30 A.M.). Phenotyping was conducted during the light phase between 9:00 A.M. and 12:00 P.M. A power analysis based on the effect size of the sex-averaged thermal nociceptive response on the hot plate on P7 in morphine-exposed mice versus saline (SAL) control mice (Cohen's $d=1.55)$ was used to estimate the required sample size using a two-tailed $t$ test in G*Power 3 (Faul et al., 2007). A sample size of 12 per treatment provides $95 \%$ power $(p<0.05)$. Thus, for the behavioral studies, we used a minimum of $n=12$ per treatment ( 6 females, 6 males). All behavioral data were generated by female experimenters, thus controlling for the sex of the experimenter as a source of variance (Bohlen et al., 2014; Sorge et al., 2014).

\section{Morphine treatment regimen from P1 through P14}

Morphine sulfate pentahydrate (Sigma-Aldrich) was dissolved in sterilized physiological saline $(0.9 \%)$ in a $0.75 \mathrm{mg} / \mathrm{ml}$ morphine solution for systemic administration via injections ( $15 \mathrm{mg} / \mathrm{kg}$, s.c., in $20 \mu \mathrm{l} / \mathrm{g}$ volume). The morphine dose is based on the total molecular weight of morphine sulfate pentahydrate (not just morphine). For P1 through P14, injections were administered twice daily mostly at 7:30 A.M. and 4:00 P.M. The only exceptions were at P7 and P14, at which time injections were administered at 10:00 A.M. and 4:00 P.M. to provide time for phenotypic assessment of spontaneous morphine withdrawal from 8:00 to 10:00 A.M. (see below). We used a mixed-litter design whereby one-half of the pups was randomly assigned to saline $(20 \mu \mathrm{l} / \mathrm{g}$, s.c.) and the other half was randomly assigned to morphine $(15 \mathrm{mg} / \mathrm{kg}$, s.c.) within the same litter. The rationale for choosing a mixed-litter design was to avoid introducing confounds between litters that could skew the results (e.g., genetic relatedness, maternal behavior, or the general cage environment). On P7, pups underwent behavioral phenotyping, as described below, $16 \mathrm{~h}$ following morphine administration. Systemically administered morphine reaches a peak plasma concentration at $15 \mathrm{~min}$ with a half-life of $\sim 37 \mathrm{~min}$ (Boasen et al., 2009). Thus, the behavioral effects associated with prior morphine exposure are attributed to withdrawal at $16 \mathrm{~h}$ following the last administration, rather than the acute, bioactive effects of morphine. Twice daily administration of morphine then continued until P14 when pups underwent behavioral phenotyping, followed by morphine administration at 10:00 A.M. and 4:00 P.M. On $\mathrm{P} 15,16 \mathrm{~h}$ after final morphine administration, mice were killed at 10:00 A.M. by live, rapid decapitation, and brain tissue was immediately harvested.

\section{General procedures}

Experimenters (all females) were blinded to saline or morphine conditions during behavioral testing on P7 and P14. Pups were habituated to the testing room for at least $1 \mathrm{~h}$ before testing. Immediately before testing, pups were transferred to a new cage containing a heat pad. Dams and sires remained in their home cages in the testing room while the pups were tested. Activity in sound-attenuating chambers during ultrasonic vocalization recording and on the hot plate were video recorded using infrared cameras (Swann) and tracked with ANY-maze tracking software (Stoelting).

\section{Ultrasonic vocalizations in P7 and P14 mice}

During maternal separation, withdrawal from repeated morphine administration increases USVs in rat pups (Barr and Wang, 1992). Before injections on P7 and $\mathrm{P} 14$, each mouse pup was placed into a Plexiglas box $(43 \mathrm{~cm}$ length $\times 20 \mathrm{~cm}$ width $\times 45 \mathrm{~cm}$ height; Lafayette Instruments) placed within sound-attenuating chambers (Med Associates). USVs were recorded using Ultrasound Recording Interface (UltraSoundGate $816 \mathrm{H}$, Avisoft Bioacoustics), and the concomitant distance traveled was calculated over $10 \mathrm{~min}$. After $10 \mathrm{~min}$, pups were removed from the boxes, weighed, and placed in a holding cage with a heating pad before nociceptive testing.

We used an unsupervised approach to categorize and compare syllable repertoires based on the similarity of their spectrotemporal patterns [mouse ultrasonic profile extraction (MUPET); Van Segbroeck et al., 2017]. Briefly, MUPET determines specific syllable types present in mouse USVs by analyzing their entire frequency structure, independent of syllable fundamental frequency or amplitude. Extracted syllable shapes were centered along time and frequency and were represented as low-dimension representations of USV patterns that captured their spectral shape and maintained the key spectrotemporal features (Bertrand et al., 2008; Joder and Schuller, 2012). Mean syllable duration was determined empirically from the distribution of syllable duration values in the saline group, then used for unsupervised analyses. Syllable thresholds were set at a minimum of $8 \mathrm{~ms}$ and a maximum of $200 \mathrm{~ms}$. Optimal syllable repertoire size was determined using multiple measures from MUPET (Bayesian information criterion, average log likelihood, overall repertoire modeling score and goodness-of-fit; data not shown). The diagonal of the cross-repertoire similarity matrix, which provides the correlations between syllable unit pairs from two different repertoires, was used to compare the shapes of syllable units between experimental groups.

\section{Thermal nociception in P7 and P14 mice}

Upon completion of USV recordings, the first pup was removed from the holding cage and placed in a Plexiglas 
cylinder (diameter, $15 \mathrm{~cm}$; height, $33 \mathrm{~cm}$ ) on a $52.5^{\circ} \mathrm{C}$ hot plate (IITC Life Science). On P7, the latency for the pup to turn onto their back was defined as the nociceptive response. The nociceptive response on P14 was the latency to flick or lick the forepaw or hindpaw, or jump. On P14, the majority of pups displayed a hindpaw lick. Pups were moved immediately following a pain response or following $30 \mathrm{~s}$ with no response. Immediately following nociceptive assessment on the hot plate, each pup was gently scruffed and the distal half of its tail was quickly lowered into a $48.5^{\circ}$ hot water bath (LX Immersion Circulator, PolyScience) and the tail-flick latency was recorded.

\section{Tattooing in P7 mice}

Following thermal nociception testing on $\mathrm{P} 7$, pups were tattooed for identification (ATS-3 General Rodent Tattoo System, AIMS). Pups were then injected with either morphine or saline and then returned to their home cage with the dam and sire.

\section{Self-righting in P4 and P7 mice}

A subset of pups was also tested for self-righting as a developmental milestone (Robinson et al., 2020). On P4 and P7, each mouse was placed onto their back with all paws facing upward, and gently stabilized by a finger. The latency for the mouse to right itself and place all paws on the surface was recorded.

\section{Open field arena}

A subset of mice underwent testing for anxiety-like behavior in the open field arena on P21. Mice could roam freely in Plexiglas boxes $(20 \mathrm{~cm}$ width $\times 43 \mathrm{~cm}$ length $\times$ $46 \mathrm{~cm}$ height) for $5 \mathrm{~min}$. Behavior was video recorded then later scored using ANY-maze software.

\section{Statistical analysis}

Data analysis was performed in R (https://www.rproject.org/), SPSS Statistics 27 (IBM), and GraphPad Prism 8.0 (GraphPad Software). Body weight, hot plate, tail withdrawal, self-righting, USV/min, and USV distance data were analyzed using multifactorial repeated-measures (RM) ANOVAs, with drug treatment and sex as between-subject factors and either age/day or time as fixedeffects repeated measures. Distance and percentage of center time in the open field were analyzed using two-way ANOVA, with drug treatment and sex as independent variables. Body weight from P1 was also analyzed using a two-way ANOVA because of partially missing data. Before all ANOVAs, data residuals for each phenotype were assessed for normality before parametric analysis. In the case of a non-normal distribution of the residuals (failed Shapiro-Wilk test for normality, $p<0.05$ ), data were percentile rank normalized as described previously (Templeton, 2011), and the Shapiro-Wilk test was repeated to confirm successful normalization $(p>0.05)$. To facilitate interpretation of the data, normalized data are presented as raw measurement values. Mauchly's test of sphericity was performed for repeated measures with more than two levels (body weight and USV analysis). If the assumption of sphericity was violated, GreenhouseGeisser-corrected statistics were reported. Homogeneity of variances was confirmed using Levene's test of equality of error variances. Post hoc comparisons were performed in the case of a significant interaction to determine group differences. Either $t$ tests (paired or unpaired) with Bonferroni correction or Tukey's HSD tests were conducted for multiple comparisons.

\section{Brainstem RNA sequencing}

On $\mathrm{P} 15,16 \mathrm{~h}$ following the final morphine injection (during a state of spontaneous morphine withdrawal), mice were killed, and brains were quickly removed to collect the brainstem containing the medulla and pons. Brainstems were transferred to tubes containing RNAlater were stored at $4^{\circ} \mathrm{C}$, then $5 \mathrm{~d}$ later were lightly blotted and transferred to new tubes to be stored at $-80^{\circ} \mathrm{C}$ until RNA extraction. RNA was extracted using TRIzol (Qiagen), ethanol precipitation, filtering columns (Qiagen), and elution with sterile, double-deionized water (Yazdani et al., 2015). Samples were diluted to $50 \mathrm{ng} / \mu \mathrm{l}$. RNA library preparation (poly-A selection) and RNA sequencing (RNA-seq) was conducted at the University of Chicago Genomics Facility on an Illumina NovaSEQ 6000 sequencing system using a NovaSEQ SP-100 bp flowcell/ reagent cassette. The 12 multiplexed, pooled samples (6 mice from saline and 6 mice from morphine groups) were sequenced (100 bp single-end) on a single lane of the twolane flowcell. We used the R/Bioconductor package "scruff" for data preprocessing, including demultiplexing, read alignment, read counting, quality checking, and data visualization (Wang et al., 2019). Reads were trimmed for quality using Trimmomatic (Bolger et al., 2014). Trimmed reads were then aligned to the mm10 mouse reference genome (Ensembl) to generate BAM files for alignment using STAR (Dobin et al., 2013). The featureCounts read summarization program was used to count reads mapping to the "exon" feature in a GTF file obtained from Ensembl (GRCm38). Differential gene expression analysis of normalized read counts from Rsubread (Liao et al., 2019) was performed in R using the exactTest function in edgeR (Robinson et al., 2010). RIN (RNA integrity number) scores from the Bioanalyzer ranged from 8.2 to 8.9 , indicating high-quality RNA for sequencing. We obtained an average of 43.7 million reads per sample (range, 35-60 million reads/sample); $97.7-98.6 \%$ of these reads had a perfect bar code match. Phred quality scores were all 36.4. Greater than $90 \%$ of the reads mapped uniquely to a single locus. FASTQ files and normalized read counts are available for download from the National Center for Biotechnology Information Gene Expression Omnibus (catalog \#GSE141066).

\section{Gene network and pathway enrichment}

Network analysis and plot generation were performed using Cytoscape software. Gene expression datasets [containing Log2 fold change $\left(\log _{2} \mathrm{FC}\right)$ and $p$ values] were uploaded for pathway analysis, and networks were plotted using known gene interactions imported from the STRING database. All genes with unadjusted 
A

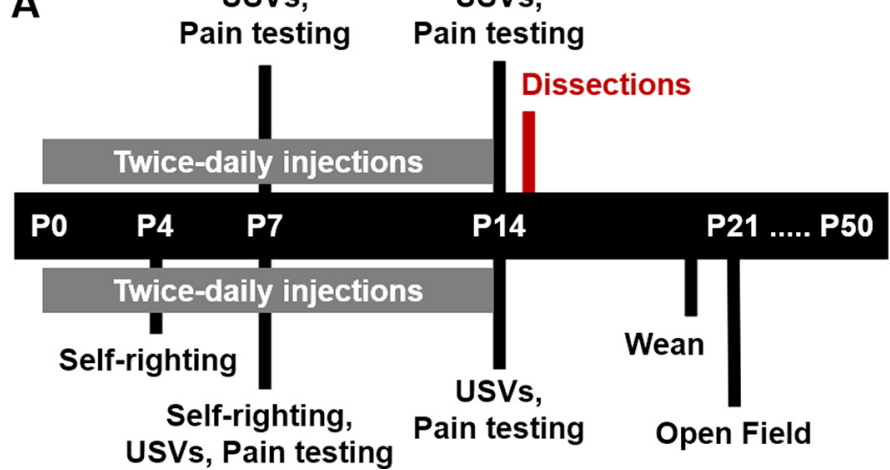

B

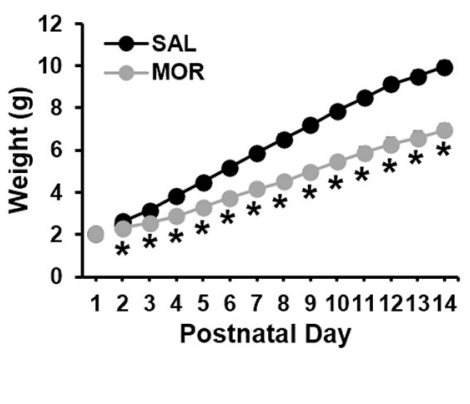

C

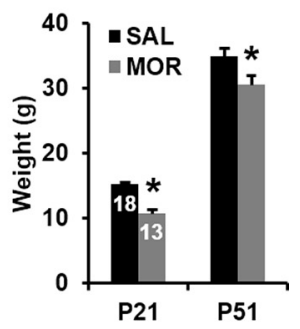

Figure 1. Experimental timeline for repeated neonatal opioid exposure and reduced weight gain. $\boldsymbol{A}$, Mice underwent assessment for USVs and thermal nociception. A subset of mice also underwent self-righting assessment at P4 and P7 and testing for locomotor activity and center time in the open field on P21. B, In examining changes in body weight, a two-way ANOVA (treatment, sex) revealed no main effect of treatment on $\mathrm{P} 1$ (saline, $n=29$; morphine, $n=25 ; F_{(1,50)}=0.61, p=0.44$ ). Thus, body weight was not significantly different between treatment groups before the first injections. There was the expected main effect of $\operatorname{sex}\left(F_{(1,50)}=11.10\right.$, $p=0.002)$ but no treatment $\times$ sex interaction $\left(F_{(1,50)}=0.78 ; p=0.31\right)$. Body weight was subsequently analyzed from $\mathrm{P} 2$ to $\mathrm{P} 14$ via RM ANOVA, with treatment and sex as factors and postnatal day as the RM. Mauchly's test indicated the assumption of sphericity had been violated $\left(\chi^{2}(77)=1711.02, p<0.001\right)$, so the Greenhouse-Geisser correction was applied $(\varepsilon=0.11)$. There was a main effect of treatment (saline, $n=41$; morphine, $\left.n=35 ; F_{(1.72)}=98.04, p<0.001\right)$, postnatal day $\left(F_{(1.36,97.97)}=1526.99, p<0.001\right)$, and treatment $\times$ postnatal day interaction $\left(F_{(1.36,97.97)}=72.61, p<0.001\right)$, but no treatment $\times \operatorname{sex} \times$ postnatal day interaction $\left(F_{(1.36,97.97)}=0.07 ; p=0.86\right)$; thus, the sex-combined data are presented. Post hoc pairwise $t$ tests revealed significantly lower body weight in the morphine group (*Bonferroni-adjusted $t$ tests; all $\left.p<3 \times 10^{-4} ; \alpha_{\text {adjusted }}=0.004\right)$. $\mathbf{C}$, In examining body weight in the subset of mice that was assessed at P21 and P51, RM ANOVA indicated a main effect of treatment $\left(F_{(1,27)}=29.09, p<0.001\right)$, sex $\left(F_{(1,27)}=25.119, p<0.001\right)$, postnatal day $\left(F_{(1,27)}=1174.26, p<0.001\right)$, and postnatal day $\times$ sex interaction $\left(F_{(1,27)}=31.17, p<0.001\right)$. In support of the treatment effect, morphine mice had significantly lower body weight compared with saline mice at both P21 $\left({ }^{*} t_{(1,29)}=-7.33 ; p<0.001\right)$ and P50 $\left({ }^{*} t_{(1,29)}=-2.27\right.$; $p=0.03)$.

$p$ values $<0.10$ were uploaded for network analysis, which enabled the detection of more broad patterns of gene expression and pathways within specific functional networks. We first analyzed the effect of morphine on gene expression within the combined analysis and included sex as a covariate. For the combined analysis, we plotted the top six GO (Gene Ontology) Biological Process networks that contained $<50$ genes to simplify viewing of the network plot and avoid overly broad enrichment terms. We then probed sex-specific effects of morphine by separately analyzing females and males, and determined the top KEGG enrichment terms and identified the gene-gene interactions as determined by STRING.

\section{Alternative splicing}

Analysis was performed using the R package ASpli (Mancini et al., 2021; Bioconductor version 1.14.0). We first performed feature extraction of the GTF annotation files to retrieve information regarding gene structure, including intron and exon bins, junctions, and intron flanking regions. Using the BAM files, we mapped RNA-seq reads to the annotated genome to determine read count density for each extracted feature. We determined differential intron/exon bin usage to identify alternative splicing events. We assessed the main effect of morphine treatment on splicing events in sex-collapsed, female-only, and male-only datasets. We also identified splicing events influenced by interactive effects of condition and sex.

\section{Correlation of read counts with P14 behavioral phenotypes}

To gain further insight into the molecular adaptations contributing to the behavioral adaptations induced by morphine, we examined the correlation between gene expression levels and phenotypes collected on P14. We specifically sought to identify genes that were differentially expressed in the morphine condition collapsed across sex and genes with normalized read counts that significantly correlated with P14 phenotypes (hot plate latency, tail withdrawal latency, USVs per minute, distance traveled during USV recordings, and body weights. Pearson product moment correlation coefficients were calculated between the normalized read counts and each of these phenotypes.

\section{Results}

\section{Reduced weight gain following neonatal morphine exposure}

A schematic of the timeline for phenotyping is provided in Figure $1 \mathrm{~A}$. Hallmarks of NOWS in human neonates are low birth weight and reduced weight gain. On P1, before morphine administration, body weights were similar across mice (Fig. 1B; saline, $n=29$; morphine, $n=25$ ). By $\mathrm{P} 2$, pups that were administered morphine $(n=35)$ already had significantly lower normalized body weights relative to saline pups $(n=41)$, and this effect persisted through P14 (Fig. 1B). Lower-body weights were also evident in morphine-exposed pups $(n=18)$ compared with the saline group $(n=18)$ at P21 and P51 in a subset of mice tested 


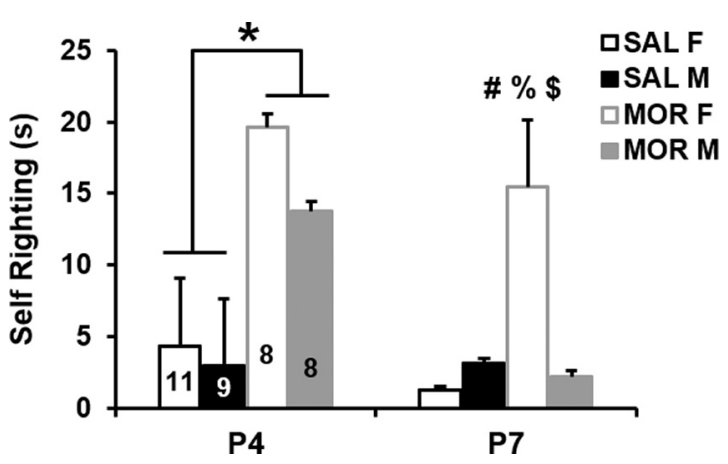

Figure 2. Altered self-righting latency in a sex-specific and development-dependent manner following repeated neonatal morphine exposure. In examining the normalized latency to self-right on P4 and P7, RM ANOVA indicated a main effect of treatment $\left(F_{(1,32)}=\right.$ 49.23; $p<0.001)$, postnatal day $\left(F_{(1,32)}=18.61, p<0.001\right)$, and sex $\left(F_{(1,32)}=8.30, p=0.007\right)$, as well as treatment $\times \operatorname{sex}\left(F_{(1,32)}=4.29\right.$, $p=0.046)$ and treatment $\times$ sex $\times$ postnatal day interactions $\left(F_{(1,32)}=4.69, p=0.038\right)$. Data from each day were then analyzed separately. On P4, two-way ANOVA indicated a main effect of treatment $\left(F_{(1,32)}=14.09 ; p<0.001\right)$, as morphine-treated mice took $8.47 \mathrm{~s}$ longer to self-right on average ( $95 \% \mathrm{Cl}$ for difference: [4.03, 12.91]; $\left.{ }^{*} p<0.001\right)$. On $P 7$, two-way ANOVA indicated a main effect of treatment $\left(F_{(1,32)}=24.24, p<0.001\right)$ and a treatment $\times$ sex interaction $\left(F_{(1,32)}=8.19 ; p=0.007\right)$ that was explained by significantly longer latencies to self-right in morphine females compared with all other groups: versus saline females $(95 \% \mathrm{Cl}$ for difference: [9.64, 27.52]; \#p < 0.001); versus saline males ([6.66, 25.36]; $\% p<0.001)$, and versus morphine males ([1.47, 20.71]; $\$ p=0.02)$. Morphine-exposed males did not differ significantly from saline control males $(p=0.49)$ or females $(p=0.12)$. Data are presented as the mean \pm SEM of raw (non-normalized) data.

for self-righting and open field behavior (Fig. 1C). Body weights for pups that died before P14 (6 of 41 morphineexposed pups, $\sim 15 \%$ ) were excluded from further analyses. Pups were identified as female or male on P14, so sex-specific mortality could not be determined. No deaths were observed in the saline group. Thus, morphine administration from $\mathrm{P} 1$ to $\mathrm{P} 14$ led to acute reductions in body weights and marked lower weight gain that persisted into adulthood.

\section{Altered self-righting latency in a sex-specific and development-dependent manner following repeated neonatal morphine exposure}

Self-righting from back to abdomen is used to test milestones associated with motor development. On P4, pups administered morphine displayed significantly prolonged normalized latencies to self-right compared with saline mice (Fig. 2). By P7, females administered morphine still exhibited prolonged self-righting latencies compared with all other groups, including morphine-treated males (Fig. 2). Together, our results suggest a morphine-induced developmental delay that was more persistent in morphine-exposed females compared with morphine-exposed males.

\section{Increases in USVs during maternal separation following repeated neonatal morphine exposure}

In rodents, USVs are thought to model a negative affective state and were used as an indicator of opioid withdrawal (Barr et al., 2011). Before running ANOVAs, USV data (cumulative USVs, P4 USVs per minute, and P7 USVs per minute) were percentile rank normalized (Templeton, 2011). We found complex relationships among treatment, sex, age, and time in the USV data. As expected, control pups receiving saline displayed an overall developmental decrease in USVs from P7 through P14 (Noirot, 1966; Fig. 3A). Notably, morphine-exposed pups emitted more USVs compared with saline pups on P14, but not on P7 (Fig. 3A), which could either be explained by a developmental delay or by spontaneous morphine withdrawal state.

We then analyzed the effects of morphine treatment and sex on USVs in a time-dependent manner (USVs per minute over a 10 min recording period). On P7, morphineexposed females emitted significantly more USVs per minute than saline control females during the first $3 \mathrm{~min}$ of the recording session (Fig. $3 B$ ). In the males-only analysis, however, there was no significant effect of morphine treatment. On P14, we detected significant elevations in USVs per minute in morphine-treated pups during minute 4 and minutes $6-10$ of the recording session (Fig. $3 C$ ). Unlike on P7, on P14, we did not detect significant effects of sex or interactions of sex with other factors. Our findings indicate that neonatal morphine exposure from $\mathrm{P} 1$ to P14 results in elevated USV rates in females that emerge early in the testing session on P7, as well as sex-independent increases in USV rates that emerge during the latter half of the 10 min testing period on $\mathrm{P} 14$.

\section{Concomitant locomotor activity during USV assessment}

While there was no effect of prior morphine exposure on normalized total distance, pups in both treatment groups traveled significantly farther on $\mathrm{P} 14$ relative to $\mathrm{P} 7$, which is likely attributable to normal motor development and increased mobility between these developmental timepoints (Fig. 4A). Analyzing average velocity (normalized distance per minute) over the $10 \mathrm{~min}$ recording period on P7 revealed significant time-dependent differences between treatment groups, with morphine pups displaying higher velocities during the first $4 \mathrm{~min}$ of USV recordings relative to saline controls (Fig. 4B). Additionally, independent of time, morphine males had higher average velocities than saline males on P7. Unlike on P7, on P14, there were no significant differences between treatment groups on P14 (treatment $\times$ time, $p=0.057$; Fig. $4 C$ ).

\section{Altered USV syllable repertoires following repeated neonatal opioid exposure}

We used MUPET (Van Segbroeck et al., 2017) to determine whether morphine exposure during early postnatal development caused changes in the spectrotemporal patterns of USV syllables. Our analysis showed an overall difference in the USV spectrotemporal patterns between P7 and P14 groups (Fig. 5; age, ${ }^{* * *} p<0.001$ for all parameters tested), suggesting that the USVs were developmentally regulated. In support of this observation, in saline controls, there was a developmental decrease in syllable duration (Fig. 5A; 43.43\%) 
A

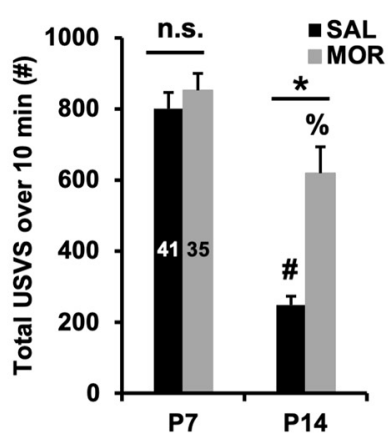

B

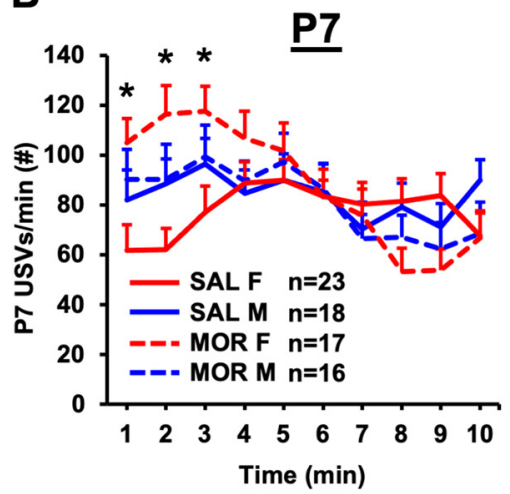

C

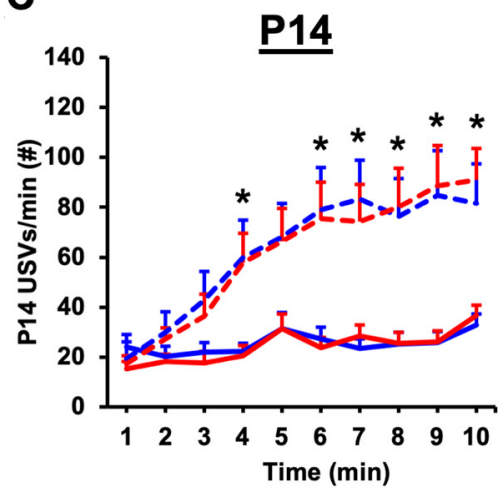

Figure 3. Pronounced increases in USVs during maternal separation following repeated neonatal morphine exposure. $\boldsymbol{A}$, In examining normalized total USVs emitted over $10 \mathrm{~min}$, RM ANOVA (treatment and sex as factors, postnatal day as the RM) revealed a main effect of treatment $\left(F_{(1,69)}=8.77, p=0.004\right)$, postnatal day $\left(F_{(1,69)}=70.89, p<0.001\right)$, and treatment $\times$ postnatal day interaction $\left(F_{(1,69)}=5.10, p=0.03\right)$. There was no effect of $\operatorname{sex}\left(F_{(1,69)}=0.05, p=0.82\right)$ and no interactions with sex (all $\left.p>0.37\right)$. Tukey's post hoc comparisons revealed no difference between treatment groups on P7 [95\% Cl for difference (saline - morphine): [-236.51, 118.56]; $p=0.82$ ]. On P14, however, morphine-treated mice emitted more USVs than saline-treated mice [95\% Cl for difference (saline - morphine): [-531.81, -173.80$\left.] ;{ }^{*} p<0.001\right]$. Both the saline- and morphine-treated groups showed a significant reduction in USVs emitted from P7 to P14 (saline group mean difference $=-555.40, \# p<0.001$; morphine group mean difference $=-261.56$, $\%$ $p=0.002)$. B, Greenhouse-Geisser corrections were applied when examining normalized USVs per minute on both P7 and P14 (Mauchly's test; P7: $\chi^{2}{ }_{(44)}=117.39, p<0.001, \varepsilon=0.69$; P14: $\chi^{2}{ }_{(44)}=155.41, p<0.001, \varepsilon=0.60$ ). On P7, RM ANOVA (treatment and sex as factors, time as the RM) identified a treatment $\times \operatorname{sex} \times$ time interaction $\left(F_{(6.22,435.22)}=2.34 ; p<0.03\right)$. Subsequent RM ANOVA of females only revealed a significant treatment $\times$ time interaction $\left(F_{(6.07,230.58)}=6.91 ; p<0.001\right)$ that was driven by elevated USVs per minute during the first $3 \mathrm{~min}$ in morphine-exposed females compared with saline-control females ( ${ }^{\star} B o n f e r r o n i$ adjusted: $p=0.004,0.009$, and 0.02 , respectively). In contrast, RM ANOVA of males only indicated no significant treatment $\times$ time interaction $\left(F_{(5.29,169.19)}=0.83 ; p=0.54\right)$ but only a main effect of time $\left(F_{(5.29,169.19)}=3.54 ; p=0.004\right)$. C, In examining normalized USVs per minute on P14, RM ANOVA (treatment and sex as factors, time as the RM) indicated main effects of treatment $\left(F_{(1,70)}=\right.$ 14.09, $p<0.001)$ and time $\left(F_{(5.41,378.88)}=34.01, p<0.001\right)$, and a treatment $\times$ time interaction $\left(F_{(5.41,378.88)}=8.19, p<0.001\right)$. There was no main effect or interaction with sex (all $p$ values $>0.47$ ). We performed unpaired $t$ tests between treatment groups (collapsed across sexes) to determine group differences across the 10 min testing period. For minutes 4 and $6-10$, morphine-exposed pups emitted significantly more USVs per minute than saline-control pups (*all Bonferroni-adjusted $p$ values $<0.03$ ). At minute 5 , the same trend was present, but was not significant (adjusted $p=0.07$ ). Data are presented as the mean \pm SEM of raw (non-normalized) data.

and an increase in intersyllable interval (Fig. 5B; $\sim 4.9$-fold change). Additionally, in $\mathrm{P} 14$ saline controls, there was an overall decrease in minimum frequency (Fig. 5C; 27.47\%), maximum frequency (Fig. $5 D ; \sim 20.82 \%$ ), mean frequency (Fig. $5 E ; \sim 27.14 \%$ ), and frequency bandwidth (Fig. 5F; $\sim 12.90 \%)$. Overall, we did not observe effects of sex or interactions with sex in our analysis (Fig. 5A-F), suggesting that the USV spectrotemporal patterns were not different between females and males.

For all the parameters measured (Fig. $5 A-F$ ), we observed an effect of treatment, suggesting that repeated morphine exposure altered the spectrotemporal patterns of USVs, relative to saline controls. Additionally, we observed an effect of postnatal day $\times$ treatment in all but one parameter measured [Fig. 5A-E (but not Fig. 5F)], suggesting that alterations in spectrotemporal USV patterns as a results of prior morphine exposure depend on postnatal day. In support, post hoc analysis indicated that for several parameters, repeated morphine administration had the most robust effects on P14 (Fig. 5A-F; syllable duration, intersyllable interval, maximum frequency, and mean frequency; saline vs chronic opioid exposure, ${ }^{* \star *} p<0.001$ ), relative to $\mathrm{P} 7$ timepoints. Last, for all the parameters measured (Fig. 5A-F), we did not observe any treatment $\times$ sex interactions or any treatment $\times \operatorname{sex} \times$ day interactions. Together, these data suggest that USV spectrotemporal patterns are developmentally regulated and are altered by repeated morphine exposure, regardless of sex.

We next categorized syllable repertoires in female and male mice administered saline (controls) and arranged repertoires based on spectrotemporal similarity (Fig. 6A$H$ ). We found that although syllable units between female and male saline mice were overall highly similar on P7 (Pearson's correlation, $0.90 \pm 0.02$; Fig. $6 /$, left, $J$ ), there were some subsets of syllable repertoires that were highly similar or distinct (Fig. $6 A-D$, red and blue squares, respectively). In contrast to the relative similarity found between the sexes at P7, Pearson's correlation values indicated a more robust difference in syllable repertoires between the reference group (saline females at P7) and both the saline female group and the saline male group at P14 (Figs. 6E-I, right, J, 7C; values obtained from the diagonal; P7 saline female group vs P14 saline female and male groups, Pearson's correlation, $\leq 0.70$ ). Overall, our findings suggest that independent from morphine exposure, our approach had the sensitivity to detect developmental changes in the spectrotemporal patterns of USV syllable repertoires of early postnatal mice. In addition, these results suggest a transition in the spectrotemporal 
A

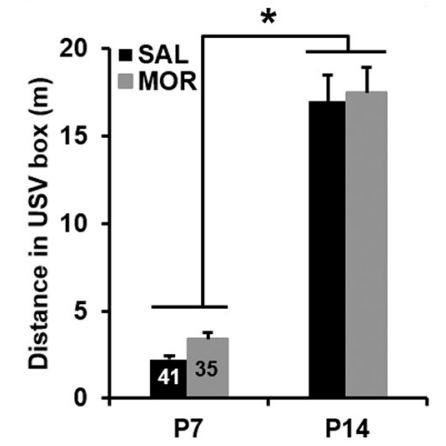

B

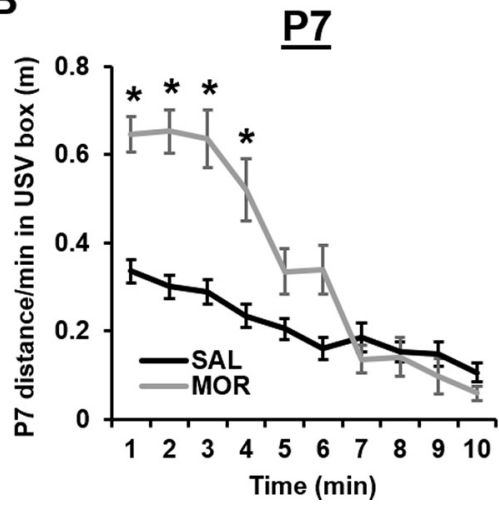

C

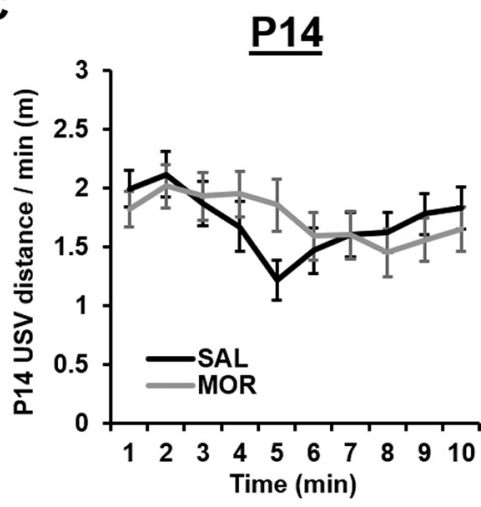

Figure 4. Concomitant locomotor activity during USV recordings following repeated neonatal morphine exposure. $\boldsymbol{A}$, RM ANOVA of normalized total distance during USV recordings (treatment and sex as factors, postnatal day as the RM) indicated no effect of treatment $\left(F_{(1,70)}=0.78 ; p=0.38\right)$, but there was a significant effect of postnatal day $\left(F_{(1,70)}=199.52\right.$, $\left.{ }^{*} p<0.001\right)$, as pups traveled an average of $14.36 \pm 1.02 \mathrm{~m}$ further on P14 versus P7. There was no effect of sex $\left(F_{(1,70)}=0.26, p=0.61\right)$, and there were no significant interactions (all $p$ values $\geq 0.59$ ). B. To detect any time-dependent effects of morphine on locomotor activity during USV recordings, we also assessed distance traveled per min. Again, data were normalized before parametric analysis and Greenhouse-Geisser corrections were applied (Mauchly's test; P7: $\chi^{2}{ }_{(44)}=135.38, p<0.001, \varepsilon=0.67 ; \mathrm{P} 14: \chi^{2}{ }_{(44)}=233.39, p<0.001, \varepsilon=0.52$ ). On P7, RM ANOVA (treatment and sex as factors, time as the RM) indicated the main effects of treatment $\left(F_{(1,71)}=0.67, p=0.04\right)$ and time $\left(F_{(6.03,428.15)}=77.96, p<0.001\right)$, and significant treatment $\times$ time $\left(F_{(6.03,428.15)}=15.81, p<0.001\right)$ and treatment $\times$ sex $\left(F_{(1,71)}=4.29\right.$, $p=0.04)$ interactions. The time $\times$ treatment interaction was driven by increased distance traveled by morphine-exposed pups during minute 1 through minute 4 of USV recordings ( ${ }^{*}$ all adjusted $p$ values $\leq 0.02$; unpaired $t$ tests with Bonferroni correction). The treatment $\times$ sex interaction was driven by an increase in distance traveled in morphine-exposed males relative to saline males $(0.12 \pm$ $0.04 \mathrm{~m}$; Bonferroni-adjusted $p=0.006$ ). $\boldsymbol{C}$, On P14, RM ANOVA (treatment and sex as factors, time as the RM) indicated a main effect of time $\left(F_{(4.7,333.70)}=4.86, p<0.001\right)$ and a near-significant time $\times$ treatment interaction $\left(F_{(4.7,333.70)}=2.21, p=0.057\right)$. There was no main effect of sex or interactions with sex ( $p$ values $>0.23$ ). In contrast to P7, there was no significant difference between saline control and morphine-exposed mice at any time point (all Bonferroni-adjusted $p$ values $\geq 0.53$ ). Data are presented as the mean \pm SEM of raw (non-normalized) data.

structure of USV syllables during the first 2 weeks of postnatal development.

At P7, Pearson's correlation values and similarity matrices indicated little effect of morphine in females or males, as demonstrated by the high correlation relative to P7 saline females (Fig. $7 A, B$, concentrated red hues in matrix diagonal) and by the sex-collapsed morphine group (Fig. $7 F$, left) relative to the $\mathrm{P} 7$ saline female reference group. These results suggest that repeated morphine administration had no detectable effect on the spectrotemporal structure of USVs on P7. Additionally, in contrast to the discordance in USV profiles noted between P7 and P14 saline mice (Figs. 6/,J, 7C, low correlation indicated by blue hues in matrix diagonal), morphine-treated mice showed greater USV profile similarity (or, i.e., less robust dissimilarity) at P14 when compared with the P7 saline reference group (Fig. 7D-F). Therefore, early developmental morphine exposure slowed the developmental trajectory of the USV spectrotemporal structure to more closely resemble the earlier $\mathrm{P} 7$ repertoire. Alternatively, the morphine spontaneous withdrawal state on P14 could mimic USV spectrotemporal effects that are consistent with a developmental delay.

\section{Thermal hyperalgesia following repeated neonatal morphine exposure}

Repeated morphine exposure from P1 to P14 led to hyperalgesia. At P7 and P14, morphine-exposed pups showed a shorter normalized latency to respond to a nociceptive stimulus relative to saline control pups on the hot plate (Fig. $8 A$ ) and tail withdrawal (Fig. 8B) assays. Morphine females tended to show enhanced hyperalgesia (shorter latencies) compared with morphine males in the tail withdrawal assay, although this result did not reach statistical significance (Fig. $8 B ; p=0.07$ ).

\section{Decreased locomotor activity in the open field at P21 following repeated neonatal morphine exposure}

We measured distance traveled and time spent in the open field arena at P21 in a subgroup of mice that were previously administered saline $(n=20)$ or morphine $(n=15)$. Prior morphine exposure was associated with decreased distance traveled compared with saline mice (Fig. 9A), and there was a nonsignificant decrease in the percentage of time spent in the center of the open field associated with morphine exposure $(p=0.053$; Fig. 9B). Both of these effects could reflect increased anxiety-like behavior and/or decreased exploratory behavior resulting from early postnatal administration of morphine.

\section{Effect of spontaneous morphine withdrawal from repeated morphine exposure on $\mathrm{P} 1$ through $\mathrm{P} 14$ on the brainstem transcriptome at $\mathrm{P} 15$}

We first compared morphine-exposed groups to saline control mice in the sex-combined dataset. Because mice were similarly administered twice daily morphine injections 


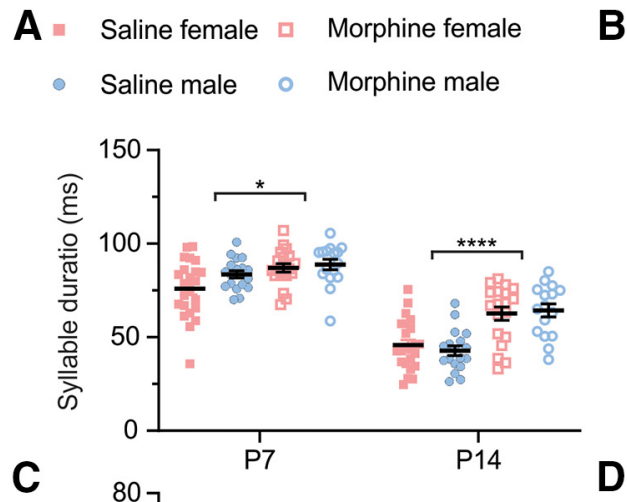

B
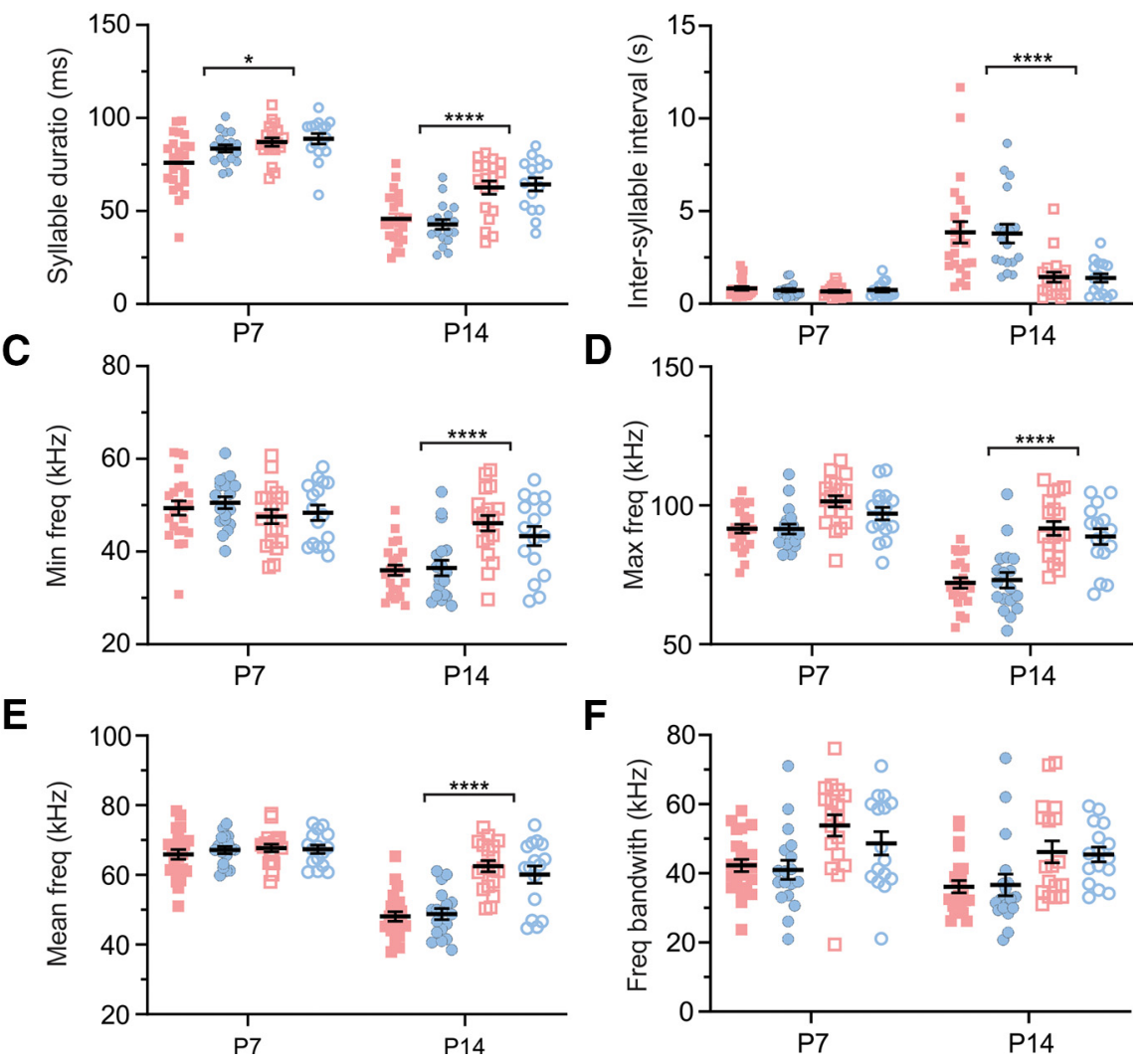

$\mathbf{F}$

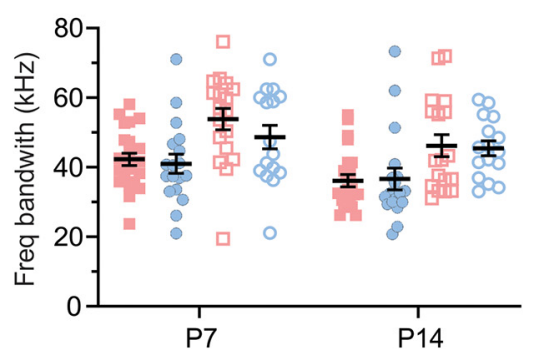

Figure 5. Changes in ultrasonic vocalizations following repeated neonatal morphine exposure. $\boldsymbol{A}$, There was an increase in normalized syllable duration in morphine-exposed females and males on P14 relative to saline controls. There were main effects of treatment $\left(F_{(1,40)}=42.97,{ }^{* \star * \star} p<0.0001\right)$, postnatal day $\left(F_{(1,40)}=240.0,{ }^{* \star *} p<0.0001\right)$, and a significant treatment $\times$ postnatal day interaction $\left(F_{(1,28)}=6.15,{ }^{*} p=0.02\right)$. There was no main effect of $\operatorname{sex}\left(F_{(1,72)}=0.75, p=0.39\right)$ or any interactions with sex (treatment $\times$ sex: $F_{(1,72)}=0.004, p=0.95$; age $\times$ treatment $\times$ sex: $\left.F_{(1,72)}=1.09, p=0.30\right)$. Tukey's post hoc comparisons revealed the following: P7: saline versus morphine, ${ }^{*} p=0.0249$; P14: saline versus morphine, ${ }^{* \star *} p<0.0001$. $\boldsymbol{B}$, Repeated morphine exposure led to a decrease in normalized intersyllable interval in female and male P14 mice relative to saline controls. There were main effects of treatment $\left(F_{(1,40)}=60.06\right.$, $\left.{ }^{* * * *} p<0.0001\right)$ and postnatal day $\left(F_{(1,40)}=138.3,{ }^{* * * *} p<0.0001\right)$ as well as a significant treatment $\times$ postnatal day interaction $\left(F_{(1,28)}=\right.$ $\left.54.82,{ }^{* * \star *} p<0.0001\right)$. Again, there were no main effects of $\operatorname{sex}\left(F_{(1,144)}=0.15, p=0.69\right)$ or any interactions with sex (treatment $\times$ sex: $F_{(1,144)}<0.001, p=0.9854$; treatment $\times$ postnatal day $\times$ sex: $\left.F_{(1,144)}=0.08, p=0.77\right)$. Tukey's post hoc comparisons revealed the following: P7: saline versus morphine, $p=0.99$; P14: saline versus morphine, ${ }^{\star * \star \star} p<0.0001$. C. Chronic opioid exposure led to an increase in normalized minimum frequency in female P14 mice relative to saline controls. There was a main effect of postnatal day $\left(F_{(1,40)}=192.10\right.$, $\left.{ }^{* * * *} p<0.0001\right)$ and a significant treatment $\times$ postnatal day interaction $\left(F_{(1,28)}=25.55,{ }^{* \star * *} p<0.0001\right)$. There was no main effect of treatment $\left(F_{(1,40)}=3.489, p=0.0691\right)$, no main effect of $\operatorname{sex}\left(F_{(1,72)}<0.001, p=0.98\right)$, and no interactions with sex (treatment $\times$ sex: $F_{(1,72)}=0.22$, $p=0.64$; treatment $\times$ postnatal day $\times$ sex: $F_{(1,72)}=0.46, p=0.50$ ). Tukey's post hoc comparisons revealed the following: P7: saline versus morphine, $p=0.28$; P14: saline versus morphine, ${ }^{* \star * *} p<0.0001$. $\boldsymbol{D}$, Repeated morphine exposure led to an overall increase in normalized maximum frequency relative to saline controls. There were main effects of treatment $\left(F_{(1,40)}=71.76,{ }^{\star \star \star *} p<0.0001\right)$ and postnatal day $\left(F_{(1,40)}=71.08,{ }^{* * \star *} p<0.0001\right)$ and a significant treatment $\times$ postnatal day interaction $\left(F_{(1,28)}=29.02,{ }^{* * * *} p<0.0001\right)$. There was no main effect of $\operatorname{sex}\left(F_{(1,72)}=0.96, p=0.33\right)$, and there were no interactions with sex (treatment $\times$ sex: $F_{(1,72)}=1.11, p=0.30$; treatment $\times$ postnatal day $\times$ sex: $F_{(1,72)}=0.10, p=0.76$ ). Tukey's post hoc comparisons revealed the following: P7: saline versus morphine, $p=0.13$; P14: saline versus morphine, ${ }^{\star \star \star \star} p<0.0001$. E. Chronic opioid exposure led to an increase in normalized mean frequency in female and male P14 mice relative to saline controls. There were main effects of treatment $\left(F_{(1,40)}=42.90,{ }^{* * * *} p<0.0001\right)$ and postnatal day $\left(F_{(1,40)}=107.1\right.$, $\left.{ }^{* \star * \star} p<0.0001\right)$, and a significant treatment $\times$ postnatal day interaction $\left(F_{(1,28)}=33.73,{ }^{* \star \star *} p<0.0001\right)$. There was no main effect of sex $\left(F_{(1,72)}=0.06, p=0.82\right)$, and there were no interactions with sex (treatment $\times$ sex: $F_{(1,72)}=0.78, p=0.38$; treatment $\times$ postnatal day $\times$ sex: $\left.F_{(1,72)}=0.16, p=0.69\right)$. Tukey's post hoc comparisons revealed the following: P7: saline versus morphine, $p=0.95$; P14: saline versus morphine, ${ }^{* * * *} p<0.0001$. $\boldsymbol{F}$. Chronic opioid exposure led to an overall increase in frequency bandwidth across groups relative to saline controls. There were main effects of both treatment $\left(F_{(1,40)}=28.50,{ }^{* \star *} p<0.0001\right)$ and postnatal day $\left(F_{(1,40)}=13.98,{ }^{* * *} p=0.0006\right)$, with no significant treatment $\times$ postnatal day interaction $\left(F_{(1,28)}=1.676, p=0.2068\right)$. There was no main effect of sex $\left(F_{(1,72)}=0.4988, p=0.4823\right)$, and there were no interactions with sex (treatment $\times$ sex: $F_{(1,72)}=0.1259, p=0.7238$; treatment $\times$ postnatal day $\times$ sex: $F_{(1,72)}=0.3515, p=0.5551$ ). For all parameters, we performed a three-way ANOVA mixed-effects model followed by a Tukey's post hoc test. 
A

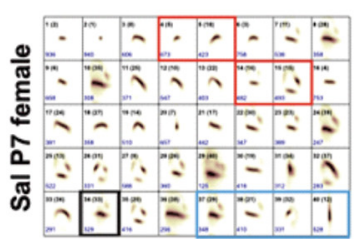

C

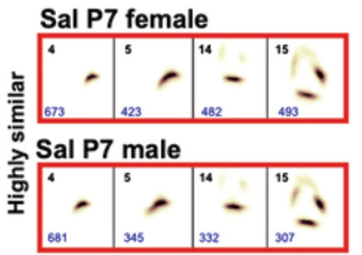

E

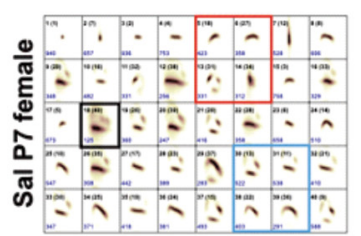

G

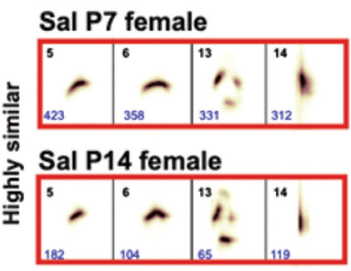

I

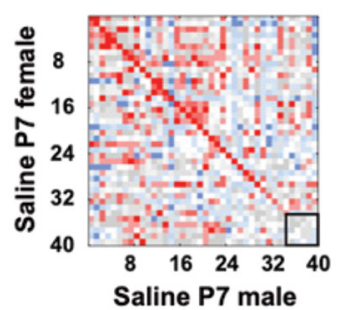

B

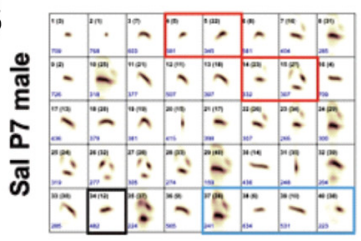

D

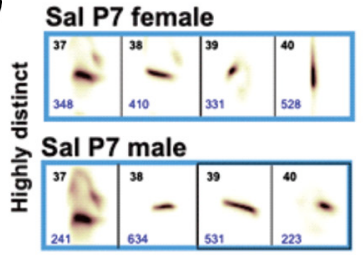

$\mathbf{F}$

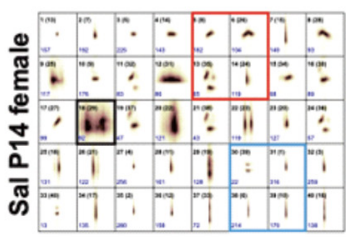

$\mathrm{H}$

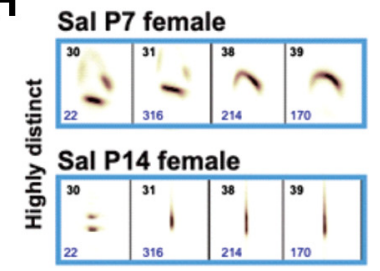

Pearson's corr.

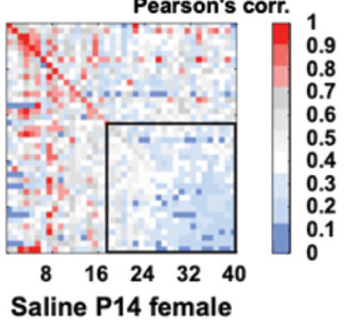

$\mathbf{J}$

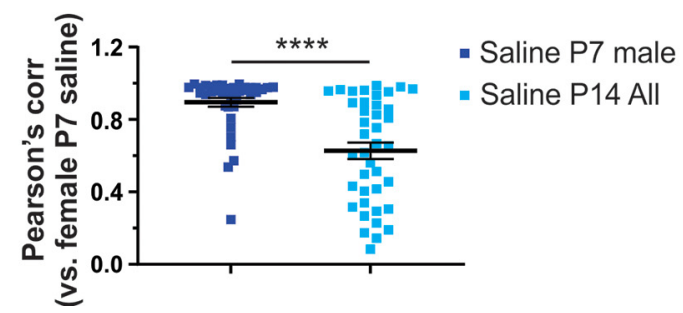

Figure 6. USV spectrotemporal structure is developmentally regulated from the first postnatal week $(P 7)$ to the second postnatal week (P14). A, B, Repertoires showing the 40 syllable types (average shape; top black numbers, syllable number) learned from processing recordings across the P7 saline datasets. Syllable types are listed in order of frequency of use from left to right (1-40), with the total number of syllables that are present in each syllable unit given in blue. Black number in parenthesis, original syllable number from datasets before performing comparison analysis. Red and blue squares are examples of highly similar or distinct syllables across groups, respectively. Pearson similarity scores are $<0.70$ after syllable labeled with bold black square. $\boldsymbol{C}, \boldsymbol{D}$, Examples of highly similar $(\boldsymbol{A}, \boldsymbol{B}$, red squares) and distinct syllables across saline $\mathrm{P} 7$ groups. $\boldsymbol{E}, \boldsymbol{F}$, Same as in $\boldsymbol{A}$ and $\boldsymbol{B}$, but syllables learned from saline P7 and P14 datasets. D-G, Examples of highly similar

continued

$(\boldsymbol{A}, \boldsymbol{B}$, red squares) and distinct syllables across saline $\mathrm{P} 7$ groups. $\boldsymbol{A}-\boldsymbol{H}$, The lower side of each syllable frame is $150 \mathrm{~ms}$. $\boldsymbol{I}$, Similarity matrix of the spectral types of pairs of syllable units learned from comparisons between reference groups (saline P7 females) and saline P7 male mice (left panel) or saline P14 female mice (right panel). The matrix diagonal gives the Pearson correlation for sequential pairs of syllables from compared datasets ranked from most to least similar (e.g., syllable 1 in both repertories are highly similar). Bold black square in the similarity matrix indicates highly distinct syllable units (Pearson score, $\leq 0.70$ ) and increases in saline P7/P14 comparison (left panel) relative to P7 comparisons (right panel), suggesting developmental regulation of USV spectrotemporal structure. I, J, Mean Pearson correlation values obtained from the diagonal in comparisons of saline P7 male (I, left) and P14 groups of both sexes (I, right; Fig. 7C) to saline P7 female mice, the "Reference Group." Red and blue values, Pearson correlations for highly similar and distinct pairs of syllables, respectively. Saline P7 males versus saline P14 sex-combined ("All"). ${ }^{\star \star \star *} p<0.0001, t$ test. Data are presented as the mean \pm SEM.

on $\mathrm{P} 14$ after phenotypic assessment, they were in a similar state of spontaneous morphine withdrawal on $\mathrm{P} 15$ when the brain tissue was harvested (10:00 A.M.; $\sim 16 \mathrm{~h}$ after the evening morphine injection on $\mathrm{P} 14$ at 4:00 P.M.). We identified $123 \mathrm{DE}$ genes at $\log _{2} \mathrm{FC}> \pm 0.26$ and $p<0.05$ (Fig. 10A, Extended Data Figs. 10-1, 10-2). Several DE genes were of interest given their potential involvement in NOWS, including the upregulation of S/c6a2, which encodes the norepinephrine transporter, and the downregulation of Onecut3, which encodes a transcription factor involved in the development of noradrenergic neurons (Espana and Clotman, 2012). We next explored the overall contribution of sex to the transcriptional changes in the brainstem induced by prior morphine exposure. In females, we identified $320 \mathrm{DE}$ genes at $\mathrm{Log}_{2} \mathrm{FC}$ $> \pm 0.26$ and $p<0.05$ (Fig. 10B, Extended Data Figs. 10-3, 10-4), including the downregulation of Nup35, a nucleoporin gene, and Serpind1, part of the serpin gene superfamily that is involved in inflammation. In males, we identified $328 \mathrm{DE}$ genes at $\log _{2} \mathrm{FC}> \pm 0.26$ and $p<0.05$ (Fig. $10 C$, Extended Data Figs. 10-5, 10-6), including Meg3, which encodes for a long noncoding RNA involved in brainstem development (Reddy et al., 2017). In addition, we found a unique set of DE genes in morphine-exposed males that was enriched for voltage-dependent calcium channels, including the upregulation of Cacna1c, Cacna1d, and Cacna1e.

We investigated the biological significance of the $D E$ genes. For the sex-combined analysis, we identified that the top enriched pathways in morphine-exposed mice were muscle contraction, embryonic organ morphogenesis, regulation of response to food, positive regulation of gene expression, anterior/posterior pattern specification, and tissue development (adjusted $p<0.05$; Fig. 11, Extended Data Fig. 11-1). For the females-only analysis, top enrichment terms included ribosome, oxidative phosphorylation, focal adhesion and protein digestion and absorption, pathways in cancer, and human papillomavirus infection (Fig. 12A, Extended Data Fig. 
A
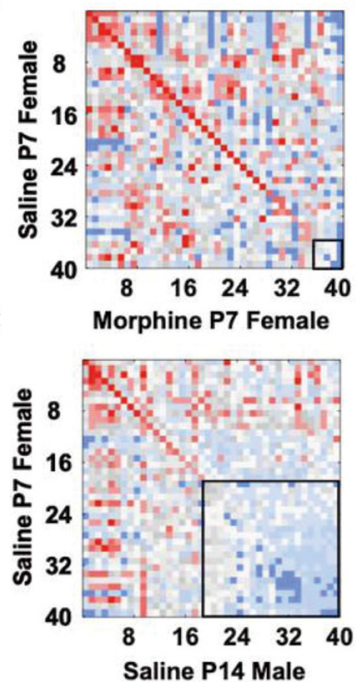

$\mathbf{E}$

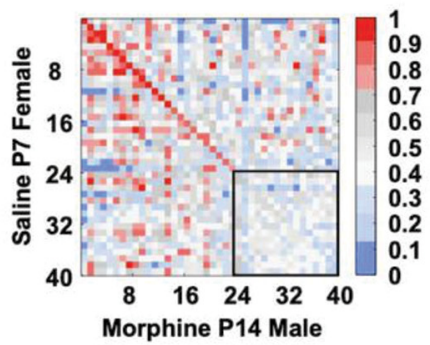

- Saline

- Morphine

$\mathbf{F}$

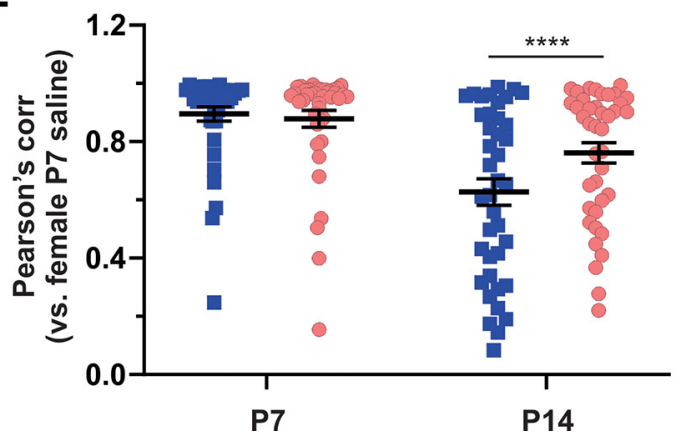

Figure 7. Changes in the spectrotemporal patterns of USV syllables following repeated neonatal morphine exposure at P7 and at P14. $\boldsymbol{A}-\boldsymbol{E}$, Following morphine exposure: similarity matrices of the spectral types of syllable unit pairs learned from reference group (saline P7 female) compared with morphine P7 female $(\boldsymbol{A})$ and male $(\boldsymbol{B})$, saline P14 male $(\boldsymbol{C})$, and morphine P14 female $(\boldsymbol{D})$ and male $(\boldsymbol{E})$. $\boldsymbol{F}$, Mean Pearson correlation values obtained from the diagonal in comparisons of all groups to the Reference Group: age: ${ }^{* \star * *} p<0.0001, F_{(1,78)}=119.30$; treatment: $p=0.20, F_{(1,78)}=1.68$; postnatal day $\times$ treatment: ${ }^{\star \star \star \star} p<0.0001$, $F_{(1,78)}=18.17$. P7 saline versus morphine, $p=0.93$; $\mathrm{P} 14$ saline versus morphine, ${ }^{*} p=0.01$. We performed a two-way RM ANOVA $\left(F_{(\mathrm{DFn}, \mathrm{DFd})}\right.$, followed by a Sidak's post-test. Data are presented as the mean \pm SEM.

12-1). The top enriched pathways in morphine-exposed males were Huntington's disease, ribosome, circadian entrainment, retrograde endocannabinoid signaling, and Alzheimer's disease.

\section{Neonatal morphine exposure impacts alternative splicing}

For all significant alternative splicing events based on differential intron/exon bin usage, see Tables 2 and 3 . There were no significant alternative splicing events for the overall effect of morphine administration. However, we identified six genes (false discovery rate, $<0.05$ ), including Ptov1, Ssbp4, Mmp2, D430019H16Rik, 1700028K03Rik, and Lrch4, that differed by sex and treatment (Table 1). Although there were no splicing events detected in the females-only dataset, several alternative splicing events were driven in part by the male-only morphine group that included Ptov1, Brdt, Cdkn1c, Tm9sf4, Gipc1, Atg2b, Cul9, and Lrch4 (Table 2). Gipc1 (called RGS19/GAIP-interacting protein 1) regulates $\mu$ opioid receptor agonist signaling (Wang and Traynor, 2013). For Cdkn1c, we detected two intronic retention events driven by the morphine males (Table 2). Cdkn1c (cyclin-dependent kinase inhibitor $1 C$ ) regulates the proliferation and differentiation of dopaminergic neurons in the midbrain (Andrews et al., 2007; McNamara et al., 2018). We also detected an intronic retention event within $\mathrm{Brdt}$ in males (Table 2), which codes for bromodomain testes-associated protein. The bromodomain and extraterminal family of scaffolding proteins are epigenetic readers that bind acetylated histones to recruit protein complexes and regulate chromatin dynamics and transcription, including cocaine-induced transcriptional regulation of brain-derived neurotrophic factor and neurobehavioral plasticity (Sartor et al., 2015) as well as mechanical allodynia induced by a combination of treatment with morphine and HIV glycoprotein 120 (Takahashi et al., 2018).

\section{Correlations of DE genes on P15 with NOWS behavioral phenotypes displayed on P14}

Notably, 75 of 139 DE genes ( $54 \%)$ correlated with at least a single behavioral phenotype at P14, and 32 of 139 DE genes $(\sim 23 \%)$ correlated with at least two phenotypes (Table 3). Interestingly, the expression of Prokr1 was significantly correlated with the most phenotypes, including body weight $(R=-0.81, p=0.001)$, hot plate latency $(R=$ $-0.58, p=0.04)$, total number of USVs $(R=0.65, p=0.02)$, and distance traveled during USV recording session $(R$ $=0.58, p=0.04$ ). In morphine-exposed mice, Prokr1 was upregulated compared with saline mice, and expression was negatively correlated with hot plate latency. Thus, upregulation of Prokr1 at P15 was associated with heightened behavioral indications of hyperalgesia at P14. Interestingly, Prokr1 (prokineticin receptor 1) codes for a GPCR for the chemokine prokineticin and is upregulated in nociceptors during tissue inflammation and contributes to inflammatory pain (Franchi et al., 2017). Thus, upregulation of Prokr1 could potentially be a critical mediator of sensory, motivational, and affective model behaviors following and during neonatal opioid withdrawal.

\section{Discussion}

We administered morphine from P1 to P14 in mouse pups, a developmental period approximating the third trimester in human neonates, to model NOWS. We found 
A

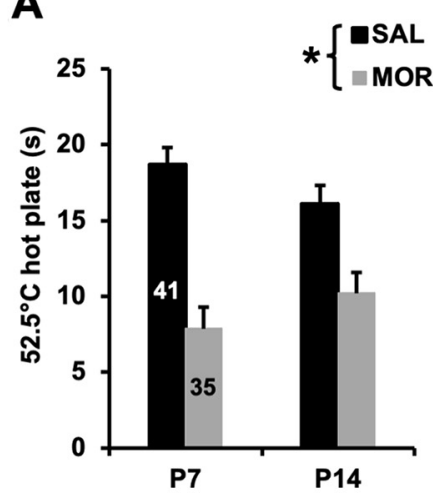

B

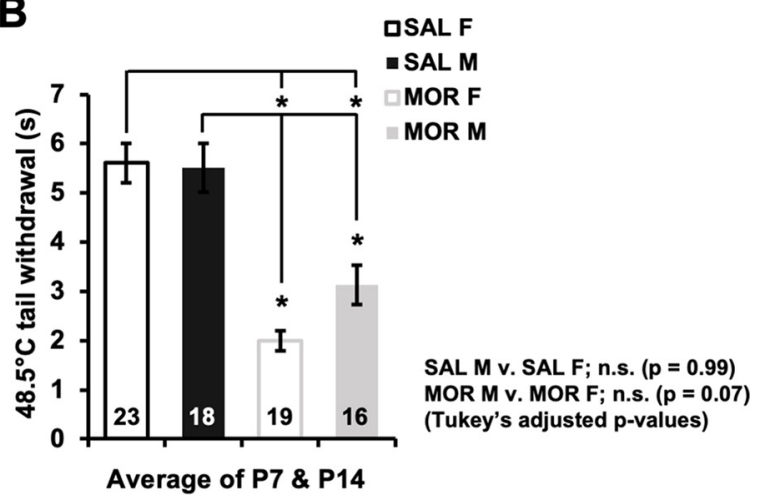

Figure 8. Thermal hyperalgesia following repeated neonatal morphine exposure. $\boldsymbol{A}$, In examining normalized thermal nociceptive sensitivity on the $52.5^{\circ} \mathrm{C}$ hot plate, RM ANOVA (treatment and sex as factors; postnatal day as the RM) revealed a main effect of treatment $\left(F_{(1,72)}=65.01\right.$, $\left.{ }^{*} p<0.001\right)$ but no effect of $\operatorname{sex}\left(F_{(1,72)}=0.52 ; p=0.47\right)$ or postnatal day $\left(F_{(1,72)}=0.04 ; p=0.85\right)$, and no interactions (all $p$ values $\geq 0.24$ ). Morphine-treated pups displayed a nociceptive response of $8.91 \pm 1.11 \mathrm{~s}$ (mean $\pm \mathrm{SEM}$ ) sooner $(p<0.001)$ than saline-treated pups on average, supporting the presence of hyperalgesia. $\boldsymbol{B}$, In examining normalized thermal nociceptive sensitivity in the $48.5^{\circ} \mathrm{C}$ tail withdrawal assay, RM ANOVA (treatment and sex as factors, postnatal day as a repeated measure) indicated a main effect of treatment $\left(F_{(1,70)}=60.98, p<0.001\right)$, postnatal day $\left(F_{(1,70)}=4.96, p=0.029\right)$, and a treatment $\times$ sex interaction $\left(F_{(1,70)}=4.83, p=0.03\right)$. However, there were no interactions with day ( $p$ values $\left.>0.19\right)$, and, thus, tail withdrawal latencies were averaged across P7 and P14 to more clearly and specifically illustrate the treatment $\times$ sex interaction. Post hoc analysis revealed lower latencies in both morphine-treated males and females relative to all saline groups (Tukey's test: SAL males vs MOR males, $p=0.002$; SAL males vs MOR females, $p<0.001$; SAL females vs MOR females, $p<0.001$; SAL females vs MOR males, $p<0.001)$. While there was no difference in latencies between saline-treated males and females $(p=0.99)$, there was a nonsignificant lower latency in morphine-treated females compared with morphine-treated males $(p=0.072)$, hinting at greater hyperalgesia. Data are presented as the mean \pm SEM of raw (non-normalized) data, averaged across P7 and P14.

several important NOWS-related phenotypes in female
A

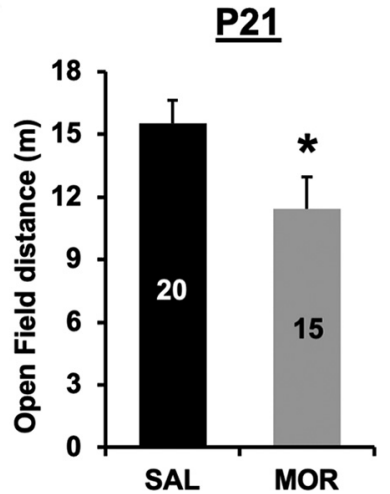

B

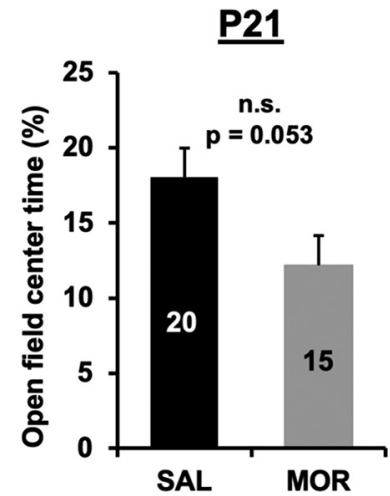

Figure 9. Decreased locomotor activity in the open field on P21 following repeated neonatal morphine exposure. $\boldsymbol{A}$, In examining distance traveled in the open field assay on P21, there was a main effect of treatment $\left(F_{(1,31)}=4.66,{ }^{*} p=0.039\right)$, indicating that morphine-exposed mice showed less locomotor activity compared with saline control mice. There was no effect of sex $\left(F_{(1,31)}=0.07, p=0.79\right)$ and no interaction $\left(F_{(1,31)}=0, p=0.99\right)$. $\boldsymbol{B}$, In examining the percentage of time spent in the center of the open field, there was a nonsignificant effect of treatment $\left(F_{(1,31)}=4.15, p=0.053\right)$. There was no effect of $\operatorname{sex}\left(F_{(1,31)}=\right.$ $0.001 ; p=0.97)$ and no treatment $\times$ sex interaction $\left(F_{(1,31)}=\right.$ $0.17 ; p=0.68)$. We note that the decreased locomotor activity in the morphine-exposed mice could concomitantly affect the overall time spent in the center and, thus, by extension, could affect the percentage of time spent in the center of the open field as an anxiety-like measure. and male mice, including reduced weight gain, developmental motor delays and USVs, agitation, and decreased locomotor activity in the open field test of anxiety-like behavior, and thermal hyperalgesia. We also discovered potential sex-specific vulnerabilities to NOWS model behaviors. In human neonates, males are more frequently diagnosed with and treated for NOWS, with no overall increase in NOWS severity compared with females (Juni et al., 2008). Increased male sensitivity to NOWS has also been found in C57BL/6J male mice, as evident by an increase in USVs (Robinson et al., 2020). However, our findings suggest that outbred CFW female mice were more sensitive to the NOWS neurobehavioral phenotypes than males (e.g., delayed latencies to self-right and increased USVs on P7), suggesting sex-specific neurodevelopmental delays in NOWS. Motor delays and an earlier emergence of increased USVs were also reported in C57BL/6J female mice (Robinson et al., 2020). Thus, repeated bouts of MOR intoxication and withdrawal during the third trimester-equivalent exposure is sufficient to induce multiple signs of neurodevelopmental delay. Overall, female mice were more vulnerable to the effects of morphine exposure during P1-P14. Importantly, we also found sexspecific transcriptional alterations in the brainstem following morphine administration, with enrichment of ribosomal and oxidative phosphorylation pathways for both sexes. Collectively, our findings begin to highlight the consequences of morphine exposure during a critical neurodevelopmental period.

Emission of USVs by pups is exhibited during distress (Hofer, 1996), and they typically peak at P7 and then decrease significantly by P14 (Elwood and Keeling, 1982). 
A

Morphine vs. Saline

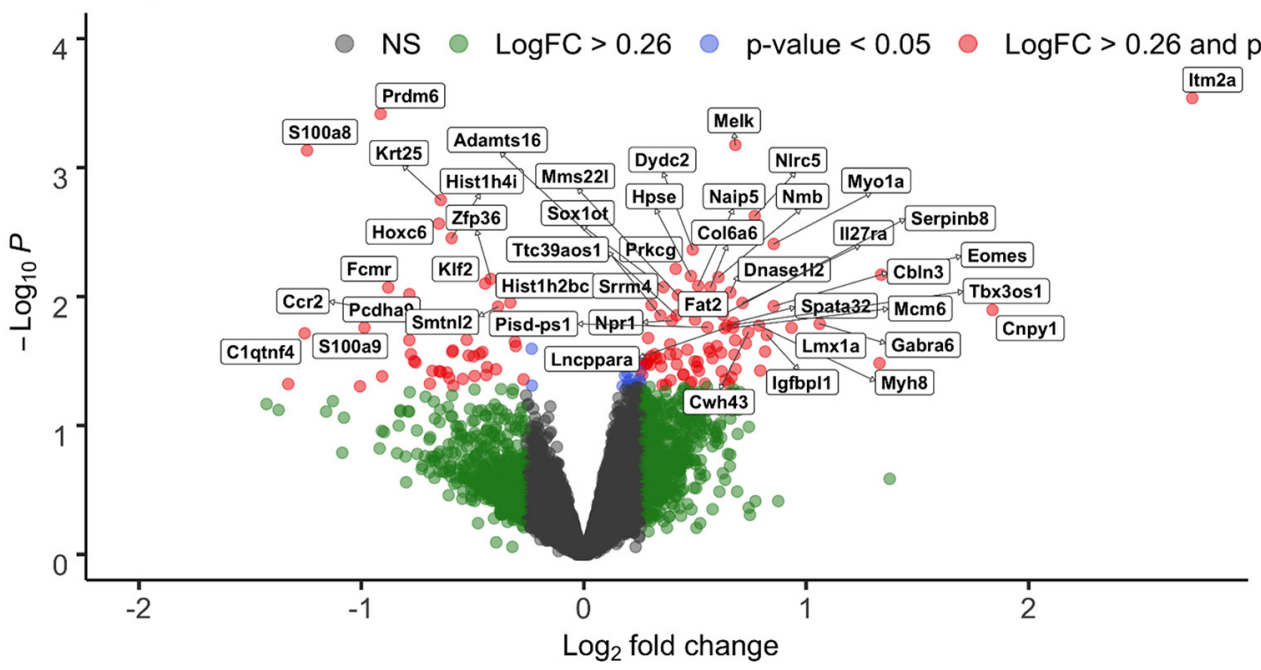

B

Females: Morphine vs. Saline

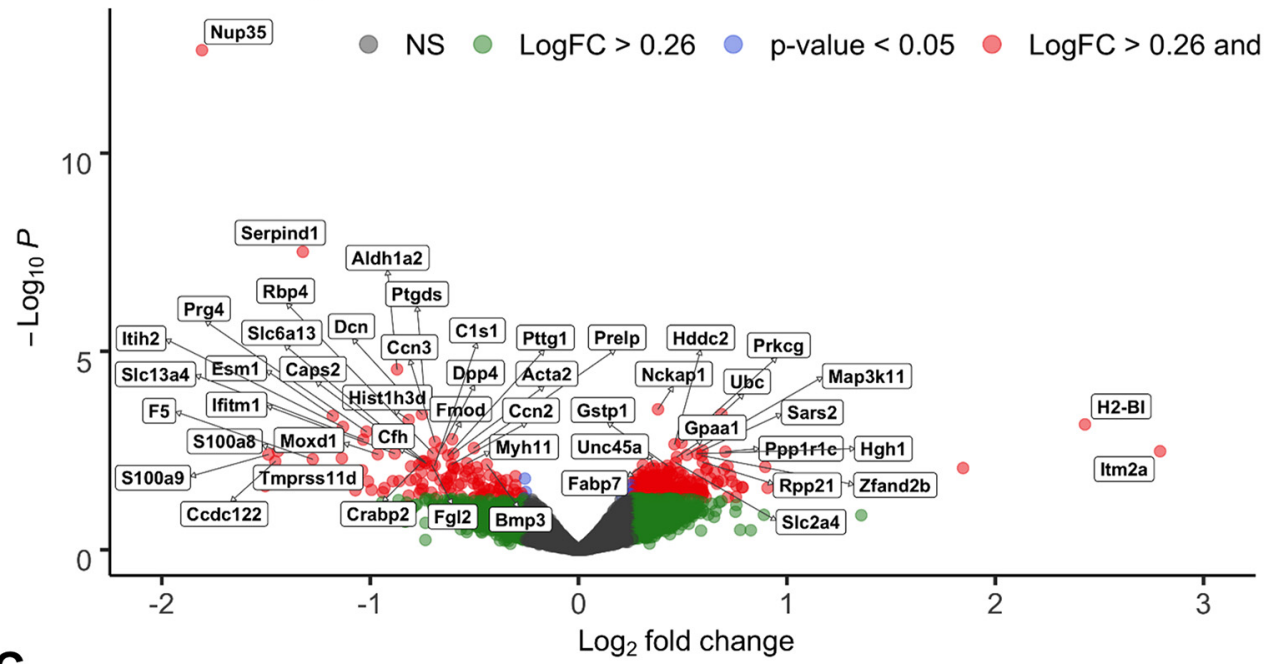

C

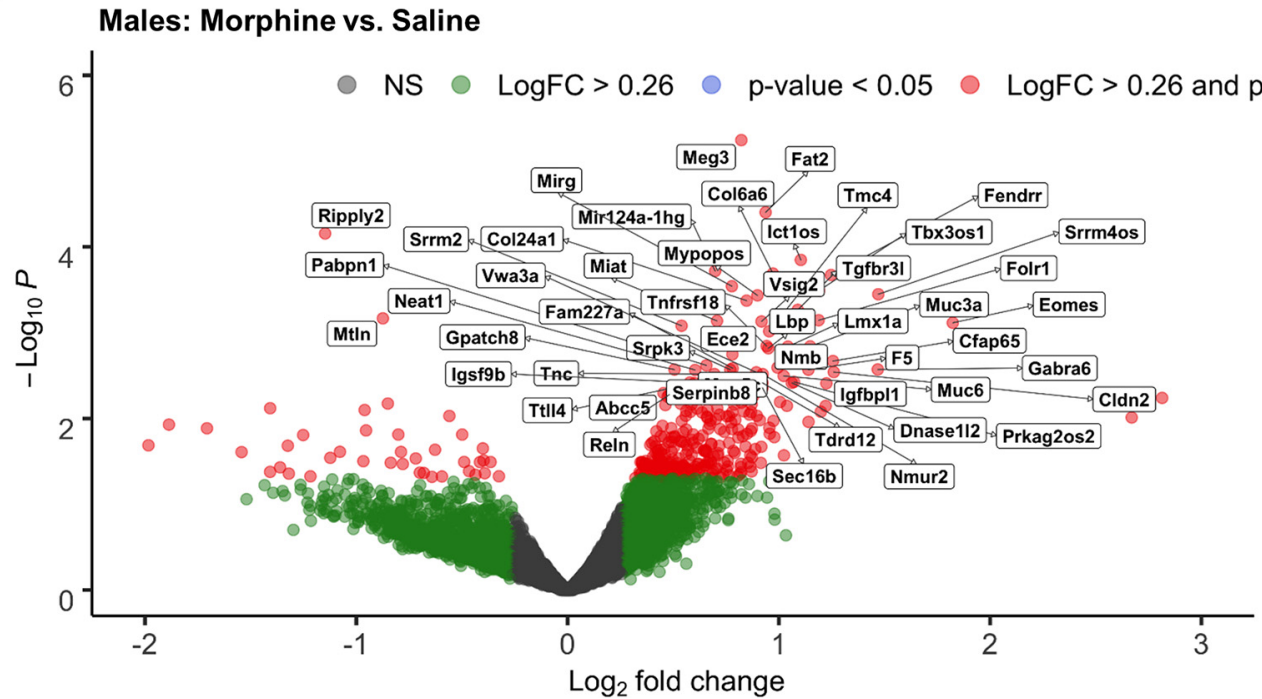

Figure 10. Differentially expressed genes in P15 brainstem tissue following repeated neonatal morphine exposure. $\boldsymbol{A}-\boldsymbol{C}$, The effect of morphine exposure on gene expression relative to saline controls in the sex-collapsed dataset $[\boldsymbol{A} ; n=6$ saline $(3$ females, 3 males), $n=6$ morphine ( 3 females, 3 males)], males only ( $\boldsymbol{B} ; n=3$ saline, $n=3$ morphine), and females only $(\boldsymbol{C} ; n=3$ saline, $n=3$ 
continued

morphine). The $x$-axis shows gene expression as LogFC, and the $y$-axis shows $\log _{10} p$ values (unadjusted). Color coding of individual genes represents LogFC $>0.26$ (green), $p<0.05$ (blue), LogFC $>0.26$ and $p<0.05$ (red), and nonsignificant (NS; gray). Complete gene lists and expression data from RNA-seq analysis are presented in Extended Data Figure 10-1 (both sexes; all genes), Extended Data Figure 10-2 (both sexes; LogFC $>0.26, p$ value $<0.05$ ), Extended Data Figure 10-3 (females; all genes), Extended Data Figure 10-4 (females LogFC > 0.26, $p$ value $<0.05$ ); Extended Data Figure 10-5 (males; all genes), Extended Data Figure 10-6 (males; LogFC $>0.26, p$-value $<0.05$ ). Data from qPCR validation of differentially expressed genes (from the sex-collapsed analysis) are presented in Extended Data Figure 10-7.

Consistent with previous studies in rats (Barr and Wang, 1992; Barr et al., 1998; Jones and Barr, 2001; Jones et al., 2002; Kalinichev and Holtzman, 2003) and mice (Robinson et al., 2020), we observed a decrease in USVs from P7 to P14 in saline control mice and, to some extent, in morphine-exposed mice, but the decrease was less pronounced in morphine-exposed mice, as indicated by a significantly greater number of USVs on P14 compared with saline control mice. The reinforcement of USVs during maternal separation may be mediated endogenous opioids (Hamed et al., 2012) as $\mu$ opioid receptors are required for this behavior (Moles et al., 2004). Thus, adaptations in endogenous opioid signaling in morphine-exposed pups could contribute to the increase in USVs on P14. Changes in USVs emerged earlier in morphine-exposed female mice compared with male mice during opioid withdrawal. An

\section{Morphine vs. Saline (Sex-Collapsed)}

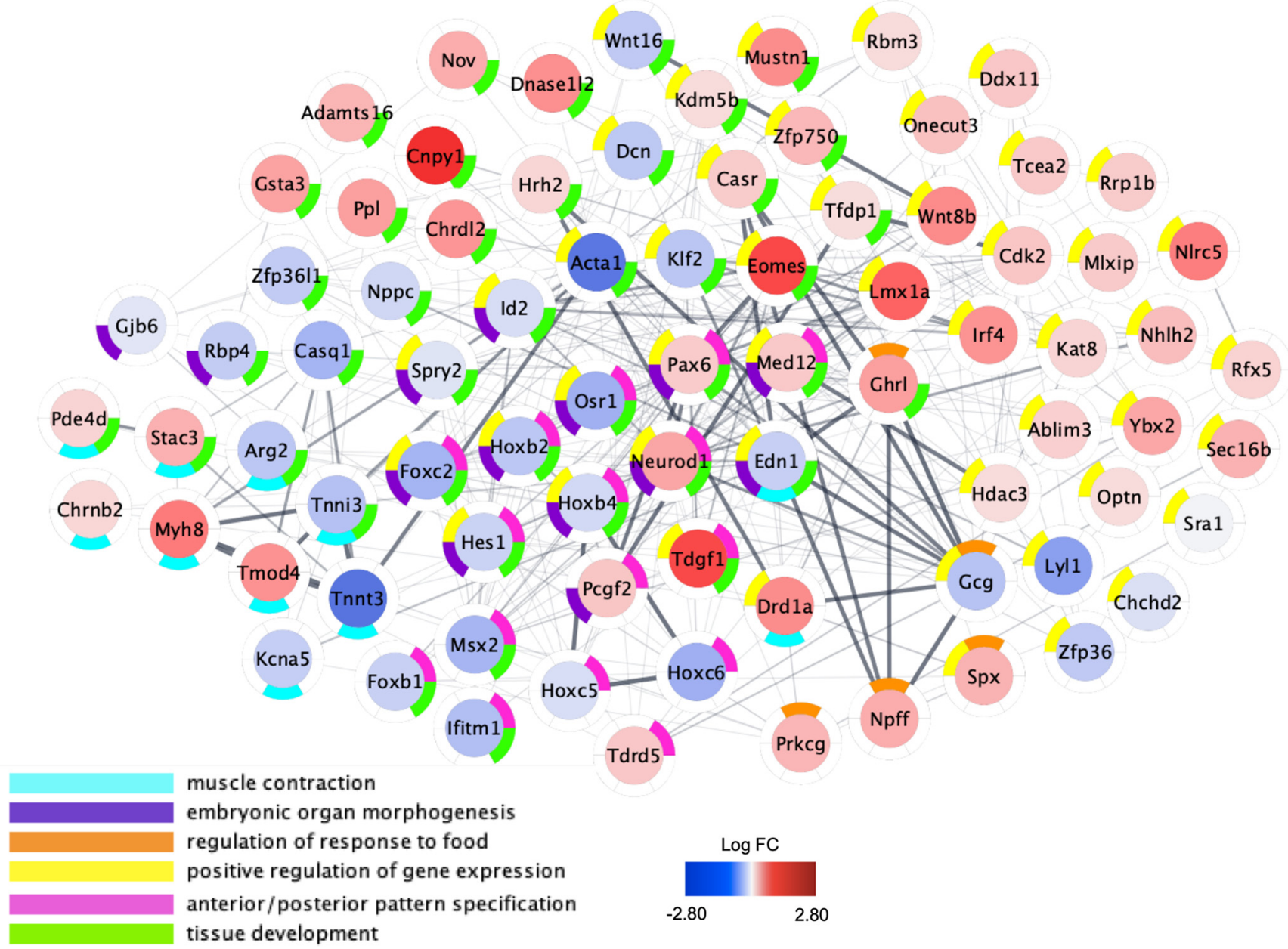

Figure 11. Functional network plot of differential brainstem gene expression on P15 following repeated neonatal morphine exposure. Plots represent gene expression relative to saline controls in sex-collapsed dataset $[n=6$ saline ( 3 females, 3 males), $n=6$ morphine (3 females, 3 males). Central color coding of individual genes reflects LogFC from -2.80 (blue) to 2.80 (red). Donut plots are color coded to reflect enriched GO Biological Process networks. All genes with unadjusted $p$ values $<0.10$ were included in functional network identification. Plots were generated using Cytoscape software, and gene interactions were imported from the STRING database to reflect known gene interactions (shown via interconnecting lines, increased line opacity represents stronger known gene interaction). Complete enrichment data for the sex-collapsed analysis are presented in Extended Data Figure 11-1. 
A

Females

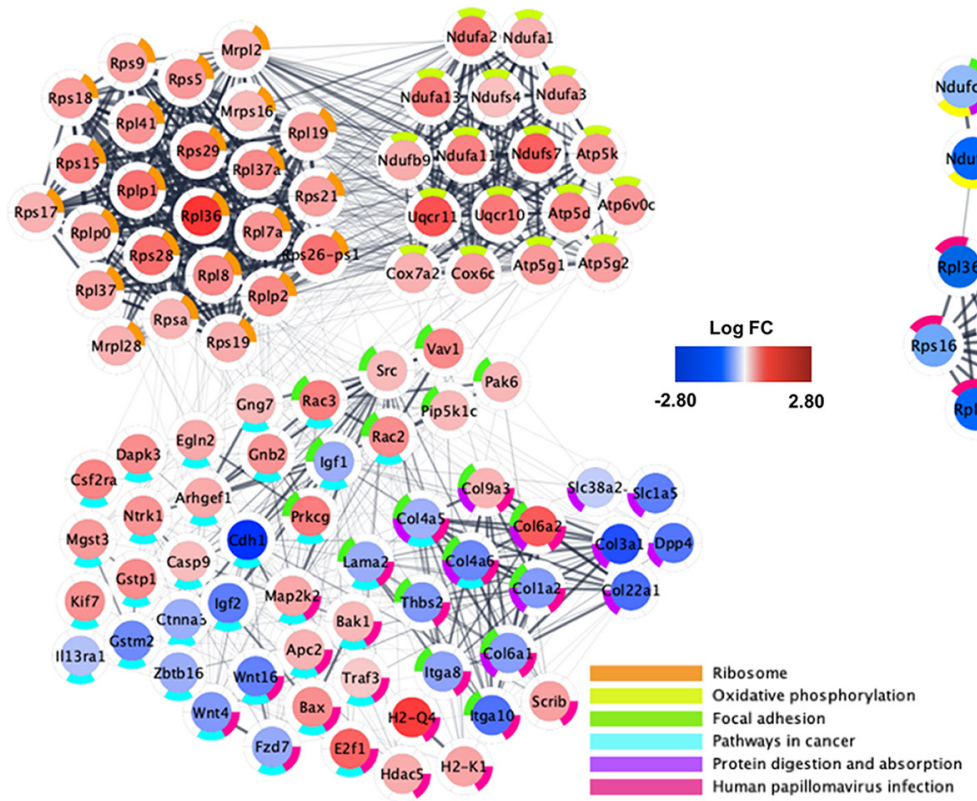

B

Figure 12. Functional network plots of differential brainstem gene expression for each sex on $\mathrm{P} 15$ following repeated neonatal morphine exposure. $\boldsymbol{A}, \boldsymbol{B}$, Plots represent gene expression relative to saline controls for females $(\boldsymbol{A} ; n=3$ saline, 3 morphine $)$ and males (B; $n=3$ saline, 3 morphine). Central color coding of individual genes reflects LogFC from -2.80 (blue) to 2.80 (red). Donut plots are color coded to reflect KEGG enrichment pathways containing $<50$ implicated genes. All genes with unadjusted $p$ values $<0.10$ were included in functional network identification. Plots were generated using Cytoscape software, and gene interactions were imported from the STRING database to reflect known gene interactions (shown via interconnecting lines, increased line opacity represents stronger known gene interaction). Complete enrichment data are presented in Extended Data Figure 12-1 (female-only analysis) and Extended Data Figure 12-2 (male-only analysis).

earlier emergence of augmented USVs in female mice contrasts with prior studies using NOWS-related models where C57BL/6J inbred males were more vulnerable to consequences of morphine on USVs (Robinson et al., 2020). Inconsistencies between these studies could be because of several factors include morphine dose, frequency and interval of morphine administration, and the time course of behavioral analysis. Another factor could be genetic background because we tested outbred CFW mice whereas a recent report that used a similar protocol used C57BL/6J mice (Robinson et al., 2020). Given our results, future studies using multiple genetic backgrounds of mice, including not only diversity outbred mice (Saul et al., 2019), but also reduced complexity crosses (Bryant et al., 2018,
2020) would be valuable for further investigating the genetic, molecular, and physiological contributions to the development of NOWS and the long-term consequences.

We found sex-specific effects on thermal nociception in our NOWS mouse model. Previous studies reported withdrawal-induced hyperalgesia and allodynia in rat pups following early neonatal opioid exposure, including increased thermal nociception (Sweitzer et al., 2004; Zhang and Sweitzer, 2008), increased formalin-induced inflammatory nociception in P11 rats (Zissen et al., 2006), and mechanical allodynia (Sweitzer et al., 2004; Zissen et al., 2007; Zhang and Sweitzer, 2008). Here, we showed that early neonatal morphine exposure was sufficient to induce hyperalgesia. Notably, this hyperalgesia emerged earlier in

Table 1: Gene transcripts showing evidence for alternative splicing in the sex-combined dataset: morphine treatment $\times$ sex interaction

\begin{tabular}{|c|c|c|c|c|c|c|c|c|c|c|c|c|c|c|}
\hline Bin_name & Symbol & Gene & Feature & Event & Locus & $\begin{array}{l}\text { Locus } \\
\text { overlap }\end{array}$ & Coordinates & Start & End & Length & $\begin{array}{l}\text { Log } \\
\text { FC }\end{array}$ & $\begin{array}{l}\text { Abs } \\
\text { LogFC }\end{array}$ & $p$ value & Bin.FDR \\
\hline 84113:E038 & 84113 & Ptov1 & $E$ & & 84,113 & & chr7:44863067-44869788 & 44867455 & 44867512 & 58 & -2.76 & 2.76 & $2.87 \mathrm{E}-07$ & 0.025 \\
\hline 76900:E029 & 76900 & Ssbp4 & $\mathrm{E}$ & & 76,900 & & chr8:70597490-70608872 & 70599525 & 70599537 & 13 & -2.93 & 2.93 & $3.96 \mathrm{E}-07$ & 0.025 \\
\hline 17390:I024 & 17390 & Mmp2 & 1 & & 17,390 & & chr8:92827291-92853420 & 28546290 & 28598105 & 51816 & -1.28 & 1.28 & 4.46E-07 & 0.025 \\
\hline 268595:1001 & 268595 & D430019H16Rik & I & & 268,595 & & chr12:105453856-105493095 & 78291839 & 78291961 & 123 & 7.63 & 7.63 & $1.04 \mathrm{E}-06$ & 0.044 \\
\hline $76421: 1007$ & 76421 & 1700028K03Rik & 1 & & 76,421 & 231,570 & chr5:107507621-107580596 & $1.33 E+08$ & $1.33 E+08$ & 484 & -8.26 & 8.26 & $1.34 \mathrm{E}-06$ & 0.045 \\
\hline 231798:E017 & 231798 & Lrch4 & $\mathrm{E}$ & & 231,798 & $1 \mathrm{E}+08$ & chr5:137629121-137641099 & $1.38 \mathrm{E}+08$ & $1.38 \mathrm{E}+08$ & 2 & -4.87 & 4.87 & $1.75 \mathrm{E}-06$ & 0.049 \\
\hline
\end{tabular}

Abs $=$ absolute 
Table 2: Gene transcripts showing evidence for alternative splicing in the males-only dataset: effect of morphine treatment

\begin{tabular}{|c|c|c|c|c|c|c|c|c|c|c|c|c|}
\hline Symbol & Gene & Feature & Event & Locus & Locus overlap & Gene coordinates & Start & End & Length & LogFC & $p$ Value & bin.FDR \\
\hline 114642 & Brdt & 1 & & 114,642 & & chr5:107331159-107387058 & $1.42 \mathrm{E}+08$ & $1.42 \mathrm{E}+08$ & 27158 & -1.38124 & $2.70 \mathrm{E}-08$ & 0.003 \\
\hline 12577 & Cdkn1c & 1 & & 12,577 & & chr7:143458339-143461050 & $1.43 E+08$ & $1.43 E+08$ & 3842 & -1.32251 & $5.20 \mathrm{E}-08$ & 0.003 \\
\hline 12577 & Cdkn1c & 1 & & 12,577 & & chr7:143458339-143461050 & $1.43 E+08$ & $1.43 E+08$ & 5304 & -1.3707 & $1.25 \mathrm{E}-07$ & 0.0047 \\
\hline 84113 & Ptov1 & $\mathrm{E}$ & & 84,113 & & chr7:44863067-44869788 & 44867455 & 44867512 & 58 & 1.98688 & $1.38 \mathrm{E}-07$ & 0.0047 \\
\hline 99237 & Tm9sf4 & 1 & & 99,237 & & chr2:153161303-153210466 & 73861694 & 73862277 & 584 & -2.91739 & 2.33E-07 & 0.0066 \\
\hline 67903 & Gipc1 & 1 & & 67,903 & & chr8:83652677-83664694 & 30900397 & 30900637 & 241 & -1.22149 & $1.83 \mathrm{E}-06$ & 0.041 \\
\hline 76559 & Atg2b & 1 & & 76,559 & & chr12:105616136-105685211 & 30121066 & 30121475 & 410 & 3.349581 & 1.93E-06 & 0.041 \\
\hline 78309 & Cul9 & $\mathrm{E}$ & & 78,309 & & chr17:46500605-46546388 & 46521041 & 46521156 & 116 & 2.133526 & $2.59 \mathrm{E}-06$ & 0.049 \\
\hline 231798 & Lrch4 & $\mathrm{E}$ & & 231,798 & $1 \mathrm{E}+08$ & chr5:137629121-137641099 & $1.38 \mathrm{E}+08$ & $1.38 \mathrm{E}+08$ & 2 & 3.464074 & $2.90 \mathrm{E}-06$ & 0.0495 \\
\hline
\end{tabular}

morphine-exposed females. Our findings support previous work in adult outbred CD-1 female mice that showed an earlier emergence and more persistent augmentation in opioidinduced hyperalgesia (Holtman and Wala, 2005; Juni et al., 2010; Arout et al., 2015). Enhanced thermal hyperalgesia and mechanical allodynia were also observed in female rats during spontaneous opioid withdrawal, although it is unknown whether similar mechanisms in the brain lead to hyperalgesia in neonatal versus adult females. Evidence suggests that neuroadaptations of NMDA receptor signaling in males may protect against the early emergence of developmental delays. Interestingly, Grin2b, the gene coding for the GluN2B subunit of the NMDA receptor, was significantly upregulated only in morphine-exposed male mice, consistent with male-specific morphine-induced neuroadaptations of the NMDA receptor system (Charles et al., 2017). Despite keeping the pups warm between behavioral testing using an electric heating pad, one limitation of this study is that we did not monitor the body temperature of the neonates throughout testing. Because hypothermia in neonatal body temperature is known to induce USVs from the pups (Branchi et al., 1998), and because opioid withdrawal in mice (Belknap, 1989) and neonatal rats (Thornton and
Smith, 1998) has been shown to be associated with hypothermia, it is possible that the detection of the effect of prior morphine exposure on USV phenotypes depends on the presence of withdrawal-induced hypothermia to evoke USV responses.

To explore potential mechanisms that contribute to sex-specific effects of early neonatal morphine on behavior, we completed RNA-seq on the brainstems of female and male mice at P15, $\sim 16 \mathrm{~h}$ following their final morphine injection. We identified distinct gene sets and enriched pathways between morphine-exposed male and female mice. In females, highly significant enrichment terms were identified for 25 ribosomal genes and several genes coding for mitochondrial proteins and oxidative phosphorylation, all of which were upregulated in response to morphine. We identified the retinaldehyde dehydrogenase, Aldh1a2, as a significantly downregulated gene in morphine-exposed females. ALDH1A2 synthesizes retinoic acid during early stages of development and has been linked to neural tube defects (Niederreither et al., 2002). Another gene involved in neurogenesis and cortical development, Cdh1 (Delgado-Esteban et al., 2013), was also reduced in the brainstems of morphine-

Table 3: Differentially expressed gene transcripts $(p<0.05)$ that significantly correlated $(p<0.05)$ with NOWS-model phenotypes on P14

\begin{tabular}{|c|c|c|c|}
\hline Phenotypes & $\begin{array}{l}\text { Overlapping } \\
\text { phenotypes, } n\end{array}$ & $\begin{array}{l}\text { Genes, } \\
n\end{array}$ & $\begin{array}{l}\text { Differentially expressed genes (MOR) } \\
\text { correlated with phenotypic data }\end{array}$ \\
\hline $\begin{array}{l}\text { Hot plate latency; normalized body } \\
\text { weight; USVs per minute }\end{array}$ & 3 & 3 & Smtnl2, Alox5ap, Adamts16 \\
\hline $\begin{array}{l}\text { Normalized body weight; USVs per } \\
\text { minute }\end{array}$ & 2 & 15 & $\begin{array}{l}\text { Hist1 h2bc, Id2, Spata32, Krt25, Hist3 h2a, Cox7b2, Zmym3, } \\
\text { Naa40, Col6a6, Srrm4, Emcn, Hpse, Miat, Mapk1ip1, Lncppara }\end{array}$ \\
\hline $\begin{array}{l}\text { Normalized body weight; tail } \\
\text { withdrawal latency }\end{array}$ & 2 & 4 & Myo1a, Plpp5, Mir3060, Mis18a \\
\hline $\begin{array}{l}\text { Tail withdrawal latency; USVs } \\
\text { per minute }\end{array}$ & 2 & 1 & Magel2 \\
\hline Tail Withdrawal Latency & 1 & 19 & $\begin{array}{l}\text { Selenov, Myom3, Ebna1bp2, II27ra, Fam92b, Ccdc116, Vipr1, Ccr2, } \\
\text { Prkcg, Rsg1, Pisd-ps1, Pisd, Arg2, Mfsd11, Mfap5, Msr1, Ifi207, } \\
\text { Foxc2, Fggy }\end{array}$ \\
\hline USVs per minute & 1 & 11 & $\begin{array}{l}\text { Timp1, Chrdl2, Cldn11, Rfc5, Plekhg4, Myh8, Snrnp200, Cpsf4l, } \\
\text { Gng11, Wdr66, Fat2 }\end{array}$ \\
\hline
\end{tabular}


exposed female mice, suggesting that morphine exposure and spontaneous withdrawal from morphine may disrupt neurodevelopmental processes by altering the expression of key genes. In addition, we identified the upregulation of genes involved in nociception, including Pnoc, a gene coding for the precursor protein to nociceptin. Nociceptin levels in the spinal cord were higher in female rats treated with morphine (Zhang et al., 2012). Together, our findings support the notion that early postnatal exposure to morphine leads to changes in nociceptin signaling, although the potential role in hyperalgesia during opioid withdrawal in neonates is unknown.

The multiple correlations that we identified between normalized read counts for the DE gene Prokr1 and behavioral phenotypes, including hot plate hyperalgesia (negative correlation with latency), USV frequency, and distance traveled during USV recordings, and its known role in inflammation and pain (Franchi et al., 2017) make this a compelling candidate mechanistic component of nociceptive, motivational, and affective components of pain during spontaneous opioid withdrawal in neonatal mice that warrants further study.

Enrichment of pathways in morphine-exposed male mice were largely distinct from those of morphine-exposed female mice. We observed several pathways enriched in male mice following morphine exposure, including circadian entrainment. Within the circadian entrainment pathway, the following genes were significantly upregulated in morphine-exposed male mice: Per3 (circadian gene); Adcyap1r1 (PACAP1 receptor); Ryr2,3 (intracellular calcium channels); Cacna1c, d,e (membrane voltage-gated calcium channels); Grin2b (NMDA receptor subunit); Kcnj6 (Kir3.2/GIRK2 potassium channel); and Kcnj13 (Kir7.1 potassium channel). Chronic morphine administration altered the expression of calcium and potassium channels in the mouse cortex and limbic system that contributes to opioid withdrawal, tolerance, and hyperalgesia (Shibasaki et al., 2007, 2010, 2011; Cruz et al., 2008; Lee et al., 2011). Importantly, circadian genes, such as Per3, which was changed in morphine-exposed male mice, have been associated with opioid-induced hyperalgesia in mice (Zhang et al., 2019) and mutations in PER3 are associated with opioid dependence in humans (Surovtseva et al., 2012). Other genes that were upregulated in morphine-exposed males include the PACAP1 receptor and ryanodine receptors, which are also associated with opioid withdrawal (Ohsawa and Kamei, 1999; Mácsai et al., 2002; Martin et al., 2003; Lipták et al., 2012).

In both females and males, we found an upregulation of Slc6a2, which encodes for the norepinephrine transporter. This transcriptional adaptation might serve to counter the increase in extracellular norepinephrine levels, a hallmark feature of opioid withdrawal (Koob, 2020). Indeed, it is well established that reducing norepinephrine release by pharmacological agonism at the $\alpha 2$ receptor with clonidine can alleviate the severity of the sympathetic component of opioid withdrawal (Gowing et al., 2016). Our findings suggest that clonidine might also be an effective treatment for autonomic symptoms in NOWS. Unfortunately, we were unable to validate the RNA-seq results via real-time quantitative PCR (Extended Data Fig. 10-7). Discordance between RNA-seq and quantitative PCR (qPCR) data are not uncommon and could be attributed not just to our limited sample size, but also to the normalization method used for RNA-seq analysis, the exons we chose to target with qPCR compared with gene-level output from RNA-seq, and/or the disparate sensitivity of these two methods of quantification (Rajkumar et al., 2015; Everaert et al., 2017). We acknowledge that our sample size for analysis with RNA-seq is small $(n=6 \mathrm{SAL}$, $n=6 \mathrm{MOR}$ ), and caution against any major conclusions before there are more in-depth studies and replication in CFW mice.

Human neonates born with NOWS often have a lower birth weight and have difficulty with postpartum weight gain. Consistent with other mouse models of NOWS (Robinson et al., 2020), we found a significant reduction in weight gain in morphine-exposed pups that persisted from P14 through weaning into adulthood. Reduced weight gain can be caused by several factors including the compromised ability to feed or reduced motivation to feed. Opioids inhibit gastrointestinal motility, inducing nausea and leading to anorexia (SantolariaFernández et al., 1995). Opioid-induced weight loss exerts profound effects on nutrition, health, and physiology in OUD (Santolaria-Fernández et al., 1995) and may be a hallmark in the transition to opioid dependence (Chen et al., 2006).

Collectively, we demonstrated sex-specific phenotypes using a NOWS model in outbred mice and revealed potential brainstem mechanisms of opioid withdrawal severity related to neurodevelopmental delays. Our studies serve as the foundation for future endeavors to examine the transcriptional changes in additional brain regions and specific cell types related to NOWS-related behavioral phenotypes. Our work establishes divergent neurobiological adaptations between females and males that could have implications for treatment and prevention of NOWS. Finally, because the sex differences we have identified contrast with previous reports on a different genetic background (Robinson et al., 2020), they suggest a potential genetic component that should be further explored on multiple genetic backgrounds.

\section{References}

Andrews SC, Wood MD, Tunster SJ, Barton SC, Surani MA, John RM (2007) Cdkn1c (p57Kip2) is the major regulator of embryonic growth within its imprinted domain on mouse distal chromosome 7. BMC Dev Biol 7:53.

Arout CA, Caldwell M, Rossi G, Kest B (2015) Spinal and supraspinal $\mathrm{N}$-methyl-D-aspartate and melanocortin-1 receptors contribute to a qualitative sex difference in morphine-induced hyperalgesia. Physiol Behav 147:364-372.

Barr GA, Wang S (1992) Tolerance and withdrawal to chronic morphine treatment in the week-old rat pup. Eur J Pharmacol 215:3542. 
Barr GA, Zmitrovich A, Hamowy AS, Liu PY, Wang S, Hutchings DE (1998) Neonatal withdrawal following pre- and postnatal exposure to methadone in the rat. Pharmacol Biochem Behav 60:97-104.

Barr GA, McPhie-Lalmansingh A, Perez J, Riley M (2011) Changing mechanisms of opiate tolerance and withdrawal during early development: animal models of the human experience. ILAR $\mathrm{J}$ 52:329-341.

Bederson JB, Fields HL, Barbaro NM (1990) Hyperalgesia during naloxone-precipitated withdrawal from morphine is associated with increased on-cell activity in the rostral ventromedial medulla. Somatosens Mot Res 7:185-203.

Belknap JK (1989) Components of the opioid withdrawal syndrome in mice are thermoregulatory responses. Pharmacol Biochem Behav 34:241-245.

Bertrand A, Demuynck K, Stouten V (2008) Unsupervised learning of auditory filter banks using non-negative matrix factorisation. In: 2008 IEEE international conference on acoustics, speech, and signal processing: Las Vegas, NV, 31 March - 4 April 2008, pp 47134716. Piscataway, $\mathrm{NJ}$ : Institute of Electrical and Electronics Engineers.

Boasen JF, McPherson RJ, Hays SL, Juul SE, Gleason CA (2009) Neonatal stress or morphine treatment alters adult mouse conditioned place preference. Neonatology 95:230-239.

Bohlen M, Hayes ER, Bohlen B, Bailoo JD, Crabbe JC, Wahlsten D (2014) Experimenter effects on behavioral test scores of eight inbred mouse strains under the influence of ethanol. Behav Brain Res 272:46-54.

Bolger AM, Lohse M, Usadel B (2014) Trimmomatic: a flexible trimmer for Illumina sequence data. Bioinformatics 30:2114-2120.

Branchi I, Santucci D, Vitale A, Alleva E (1998) Ultrasonic vocalizations by infant laboratory mice: a preliminary spectrographic characterization under different conditions. Dev Psychobiol 33:249256.

Bryant CD, Ferris MT, De Villena FPM, Damaj MI, Kumar V, Mulligan MK (2018) Reduced complexity cross design for behavioral genetics. In: Molecular-genetic and statistical techniques for behavioral and neural research (Gerlai RT, ed), pp 165-190. London: Academic.

Bryant CD, Smith DJ, Kantak KM, Nowak TS, Williams RW, Damaj MI, Redei EE, Chen H, Mulligan MK (2020) Facilitating complex trait analysis via reduced complexity crosses. Trends Genet 36:549-562.

Byrnes EM, Vassoler FM (2018) Modeling prenatal opioid exposure in animals: current findings and future directions. Front Neuroendocrinol 51:1-13.

Charles MK, Cooper WO, Jansson LM, Dudley J, Slaughter JC, Patrick SW (2017) Male sex associated with increased risk of neonatal abstinence syndrome. Hosp Pediatr 7:328-334.

Chen H-H, Chiang Y-C, Yuan ZF, Kuo C-C, Lai M-D, Hung T-W, Ho I-K, Chen S-T (2015) Buprenorphine, methadone, and morphine treatment during pregnancy: behavioral effects on the offspring in rats. Neuropsychiatr Dis Treat 11:609-618.

Chen SA, O'Dell LE, Hoefer ME, Greenwell TN, Zorrilla EP, Koob GF (2006) Unlimited access to heroin self-administration: independent motivational markers of opiate dependence. Neuropsychopharmacology 31:2692-2707.

Cruz HG, Berton F, Sollini M, Blanchet C, Pravetoni M, Wickman K, Lüscher C (2008) Absence and rescue of morphine withdrawal in GIRK/Kir3 knock-out mice. J Neurosci 28:4069-4077.

Delgado-Esteban M, García-Higuera I, Maestre C, Moreno S, Almeida A (2013) APC/C-Cdh1 coordinates neurogenesis and cortical size during development. Nat Commun 4:2879.

Desai RJ, Huybrechts KF, Hernandez-Diaz S, Mogun H, Patorno E, Kaltenbach K, Kerzner LS, Bateman BT (2015) Exposure to prescription opioid analgesics in utero and risk of neonatal abstinence syndrome: population based cohort study. BMJ 350:h2102.

Dobin A, Davis CA, Schlesinger F, Drenkow J, Zaleski C, Jha S, Batut P, Chaisson M, Gingeras TR (2013) STAR: ultrafast universal RNA-seq aligner. Bioinformatics 29:15-21.
Elwood RW, Keeling F (1982) Temporal organization of ultrasonic vocalizations in infant mice. Dev Psychobiol 15:221-227.

Espana A, Clotman F (2012) Onecut factors control development of the locus coeruleus and of the mesencephalic trigeminal nucleus. Mol Cell Neurosci 50:93-102.

Everaert C, Luypaert M, Maag JLV, Cheng QX, Dinger ME, Hellemans J, Mestdagh P (2017) Benchmarking of RNA-sequencing analysis workflows using whole-transcriptome RT-qPCR expression data. Sci Rep 7:1559.

Faul F, Erdfelder E, Lang AG, Buchner A (2007) G*Power 3: a flexible statistical power analysis program for the social, behavioral, and biomedical sciences. Behav Res Methods 39:175-191.

Fodor A, Tímár J, Zelena D (2014) Behavioral effects of perinatal opioid exposure. Life Sci 104:1-8.

Franchi S, Sacerdote P, Panerai A (2017) The prokineticin system: an interface between neural inflammation and pain. Neurol Sci 38:2730.

Gonzales NM, Palmer AA (2014) Fine-mapping QTLs in advanced intercross lines and other outbred populations. Mamm Genome 25:271-292.

Gonzales NM, Seo J, Hernandez Cordero AI, St Pierre CL, Gregory JS, Distler MG, Abney M, Canzar S, Lionikas A, Palmer AA (2018) Genome wide association analysis in a mouse advanced intercross line. Nat Commun 9:5162.

Gowing L, Farrell M, Ali R, White JM (2016) Alpha ${ }_{2}$-adrenergic agonists for the management of opioid withdrawal. Cochrane Database Syst Rev 2016: CD002024.

Hamed A, Taracha E, Szyndler J, Krząścik P, Lehner M, Maciejak P, Skórzewska A, Płaz"nik A (2012) The effects of morphine and morphine conditioned context on $50 \mathrm{kHz}$ ultrasonic vocalisation in rats. Behav Brain Res 229:447-450.

Hofer MA (1996) Multiple regulators of ultrasonic vocalization in the infant rat. Psychoneuroendocrinology 21:203-217.

Holtman JR, Wala EP (2005) Characterization of morphine-induced hyperalgesia in male and female rats. Pain 114:62-70.

Jansson LM, Patrick SW (2019) Neonatal abstinence syndrome. Pediatr Clin North Am 66:353-367.

Joder C, Schuller B (2012) Exploring nonnegative matrix factorization for audio classification: application to speaker recognition. In: 2012 ITG symposium on speech communication: 26-28 Sept. 2012, Braunschweig, Germany, pp 1-4. Piscataway, NJ: Institute of Electrical and Electronics Engineers.

Jones KL, Barr GA (1995) Ontogeny of morphine withdrawal in the rat. Behav Neurosci 109:1189-1198.

Jones KL, Barr GA (2001) Injections of an opioid antagonist into the locus coeruleus and periaqueductal gray but not the amygdala precipitates morphine withdrawal in the 7-day-old rat. Synapse 39:139-151.

Jones KL, Zhu H, Jenab S, Du T, Inturrisi CE, Barr GA (2002) Attenuation of acute morphine withdrawal in the neonatal rat by the competitive NMDA receptor antagonist LY235959. Neuropsychopharmacology 26:301-310.

Juni A, Klein G, Kowalczyk B, Ragnauth A, Kest B (2008) Sex differences in hyperalgesia during morphine infusion: effect of gonadectomy and estrogen treatment. Neuropharmacology 54:1264-1270.

Juni A, Cai M, Stankova M, Waxman AR, Arout C, Klein G, Dahan A, Hruby VJ, Mogil JS, Kest B (2010) Sex-specific mediation of opioid-induced hyperalgesia by the melanocortin-1 receptor. Anesthesiology 112:181-188.

Kalinichev M, Holtzman SG (2003) Changes in urination/defecation, auditory startle response, and startle-induced ultrasonic vocalizations in rats undergoing morphine withdrawal: similarities and differences between acute and chronic dependence. J Pharmacol Exp Ther 304:603-609.

Kaplan H, Fields HL (1991) Hyperalgesia during acute opioid abstinence: evidence for a nociceptive facilitating function of the rostral ventromedial medulla. J Neurosci 11:1433-1439.

Koob GF (2020) Neurobiology of opioid addiction: opponent process, hyperkatifeia, and negative reinforcement. Biol Psychiatry 87:44-53. 
Lee M, Silverman SM, Hansen H, Patel VB, Manchikanti L (2011) A comprehensive review of opioid-induced hyperalgesia. Pain Physician 14:145-161.

Liao Y, Smyth GK, Shi W (2019) The R package Rsubread is easier, faster, cheaper and better for alignment and quantification of RNA sequencing reads. Nucleic Acids Res 47:e47.

Lipták N, Dochnal R, Babits A, Csabafi K, Szakács J, Tóth G, Szabó G (2012) The effect of pituitary adenylate cyclase-activating polypeptide on elevated plus maze behavior and hypothermia induced by morphine withdrawal. Neuropeptides 46:11-17.

Mácsai M, Pataki I, Tóth G, Szabó G (2002) The effects of pituitary adenylate cyclase-activating polypeptide on acute and chronic morphine actions in mice. Regul Pept 109:57-62.

Maeda T, Kishioka S, Inoue N, Shimizu N, Fukazawa Y, Ozaki M, Yamamoto H (2002) Naloxone-precipitated morphine withdrawal elicits increases in c-fos mRNA expression in restricted regions of the infant rat brain. Jpn J Pharmacol 90:270-275.

Mancini E, Rabinovich A, Iserte J, Yanovsky M, Chernomoretz A (2021) ASpli: analysis of alternative splicing using RNA-Seq. Bioinformatics 37: btab141, p 1783.

Martin M, Otto C, Santamarta MT, Torrecilla M, Pineda J, Schütz G, Maldonado R (2003) Morphine withdrawal is modified in pituitary adenylate cyclase-activating polypeptide type I-receptor-deficient mice. Brain Res Mol Brain Res 110:109-118.

McNamara GI, Davis BA, Browne M, Humby T, Dalley JW, Xia J, John RM, Isles AR (2018) Dopaminergic and behavioural changes in a loss-of-imprinting model of Cdkn1c. Genes Brain Behav 17:149-157.

McPhie AA, Barr GA (2009) Regional Fos expression induced by morphine withdrawal in the 7-day-old rat. Dev Psychobiol 51:544552.

Milliren CE, Gupta M, Graham DA, Melvin P, Jorina M, Ozonoff A (2018) Hospital variation in neonatal abstinence syndrome incidence, treatment modalities, resource use, and costs across pediatric hospitals in the United States, 2013 to 2016. Hosp Pediatr 8:15-20.

Minakova E, Sarafinovska S, Mikati MO, Barclay KM, McCullough KB, Dougherty JD, Al-Hasani R, Maloney SE (2021) Ontogenetic oxycodone exposure affects early life communicative behaviors, sensorimotor reflexes, and weight trajectory in mice. Front Behav Neurosci 15:615798.

Moles A, Kieffer BL, D'Amato FR (2004) Deficit in attachment behavior in mice lacking the mu-opioid receptor gene. Science 304:1983-1986.

Niederreither K, Abu-Abed S, Schuhbaur B, Petkovich M, Chambon $P$, Dollé $P$ (2002) Genetic evidence that oxidative derivatives of retinoic acid are not involved in retinoid signaling during mouse development. Nat Genet 31:84-88.

Noirot E (1966) Ultra-sounds in young rodents. I. Changes with age in albino mice. Anim Behav 14:459-462.

Ohsawa M, Kamei J (1999) Role of intracellular calcium on the modulation of naloxone-precipitated withdrawal jumping in morphinedependent mice by diabetes. Brain Res 815:424-430.

Ossipov MH, Lai J, King T, Vanderah TW, Porreca F (2005) Underlying mechanisms of pronociceptive consequences of prolonged morphine exposure. Biopolymers 80:319-324.

Parker CC, Gopalakrishnan S, Carbonetto P, Gonzales NM, Leung E, Park YJ, Aryee E, Davis J, Blizard DA, Ackert-Bicknell CL, Lionikas A, Pritchard JK, Palmer AA (2016) Genome-wide association study of behavioral, physiological and gene expression traits in outbred CFW mice. Nat Genet 48:919-926.

Rajkumar AP, Qvist P, Lazarus R, Lescai F, Ju J, Nyegaard M, Mors O, Børglum AD, Li Q, Christensen JH (2015) Experimental validation of methods for differential gene expression analysis and sample pooling in RNA-seq. BMC Genomics 16:548.

Reddy AS, O'Brien D, Pisat N, Weichselbaum CT, Sakers K, Lisci M, Dalal JS, Dougherty JD (2017) A comprehensive analysis of cell type-specific nuclear RNA from neurons and glia of the brain. Biol Psychiatry 81:252-264.
Robinson MD, McCarthy DJ, Smyth GK (2010) edgeR: a Bioconductor package for differential expression analysis of digital gene expression data. Bioinformatics 26:139-140.

Robinson SA, Jones AD, Brynildsen JK, Ehrlich ME, Blendy JA (2020) Neurobehavioral effects of neonatal opioid exposure in mice: influence of the OPRM1 SNP. Addict Biol 25:e12806.

Ryan G, Dooley J, Gerber Finn L, Kelly L (2019) Nonpharmacological management of neonatal abstinence syndrome: a review of the literature. J Matern Fetal Neonatal Med 32:1735-1740.

Santolaria-Fernández FJ, Gómez-Sirvent JL, González-Reimers CE, Batista-López JN, Jorge-Hernández JA, Rodríguez-Moreno F, Martínez-Riera A, Hernández-García MT (1995) Nutritional assessment of drug addicts. Drug Alcohol Depend 38:11-18.

Sartor GC, Powell SK, Brothers SP, Wahlestedt C (2015) Epigenetic readers of lysine acetylation regulate cocaine-induced plasticity. $J$ Neurosci 35:15062-15072.

Saul MC, Philip VM, Reinholdt LG, Chesler EJ (2019) High-diversity mouse populations for complex traits. Trends Genet 35:501-514.

Semple BD, Blomgren K, Gimlin K, Ferriero DM, Noble-Haeusslein LJ (2013) Brain development in rodents and humans: identifying benchmarks of maturation and vulnerability to injury across species. Prog Neurobiol 106-107:1-16.

Shibasaki M, Katsura M, Kurokawa K, Torigoe F, Ohkuma S (2007) Regional differences of L-type high voltage-gated calcium channel subunit expression in the mouse brain after chronic morphine treatment. J Pharmacol Sci 105:177-183.

Shibasaki M, Kurokawa K, Ohkuma S (2010) Upregulation of L-type $\mathrm{Ca}(\mathrm{v}) 1$ channels in the development of psychological dependence. Synapse 64:440-444.

Shibasaki M, Kurokawa K, Mizuno K, Ohkuma S (2011) Up-regulation of $\mathrm{Ca}(\mathrm{v}) 1.2$ subunit via facilitating trafficking induced by Vps34 on morphine-induced place preference in mice. Eur $\mathrm{J}$ Pharmacol 651:137-145.

Sorge RE, Martin LJ, Isbester KA, Sotocinal SG, Rosen S, Tuttle AH, Wieskopf JS, Acland EL, Dokova A, Kadoura B, Leger P, Mapplebeck JCS, McPhail M, Delaney A, Wigerblad G, Schumann AP, Quinn T, Frasnelli J, Svensson Cl, Sternberg WF, et al. (2014) Olfactory exposure to males, including men, causes stress and related analgesia in rodents. Nat Methods 11:629-632.

Surovtseva MN, Kudryavtseva EA, Voronina EN, Pronin SV, Filipenko $\mathrm{ML}$ (2012) Association of the 54-nucleotide repeat polymorphism of hPer3 with opioid dependence in residents of the West Siberian region. Psychiatr Genet 22:309-310.

Sutter MB, Leeman L, Hsi A (2014) Neonatal opioid withdrawal syndrome. Obstet Gynecol Clin North Am 41:317-334.

Sweitzer SM, Allen CP, Zissen MH, Kendig JJ (2004) Mechanical allodynia and thermal hyperalgesia upon acute opioid withdrawal in the neonatal rat. Pain 110:269-280.

Takahashi K, Yi H, Liu C-H, Liu S, Kashiwagi Y, Patin DJ, Hao S (2018) Spinal bromodomain-containing protein 4 contributes to neuropathic pain induced by HIV glycoprotein 120 with morphine in rats. Neuroreport 29:441-446.

Templeton GF (2011) A two-step approach for transforming continuous variables to normal: implications and recommendations for IS research. Communications of the Association for Information Systems 28: .

Thornton SR, Smith FL (1998) Long-term alterations in opiate antinociception resulting from infant fentanyl tolerance and dependence. Eur J Pharmacol 363:113-119.

Tuttle AH, Philip VM, Chesler EJ, Mogil JS (2018) Comparing phenotypic variation between inbred and outbred mice. Nat Methods 15:994-996.

Vanderah TW, Suenaga NM, Ossipov MH, Malan TP, Lai J, Porreca F (2001) Tonic descending facilitation from the rostral ventromedial medulla mediates opioid-induced abnormal pain and antinociceptive tolerance. J Neurosci 21:279-286.

Van Segbroeck M, Knoll AT, Levitt P, Narayanan S (2017) MUPETMouse Ultrasonic Profile ExTraction: a signal processing tool for rapid and unsupervised analysis of ultrasonic vocalizations. Neuron 94:465-485.e5. 
Vera-Portocarrero LP, Ossipov MH, Lai J, King T, Porreca F (2011) Descending facilitatory pathways from the rostroventromedial medulla mediate naloxone-precipitated withdrawal in morphine-dependent rats. J Pain 12:667-676.

Wachman EM, Schiff DM, Silverstein M (2018) Neonatal abstinence syndrome: advances in diagnosis and treatment. JAMA 319:1362-1374.

Wang Q, Traynor JR (2013) Modulation of $\mu$-opioid receptor signaling by RGS19 in SH-SY5Y cells. Mol Pharmacol 83:512-520.

Wang Z, Hu J, Johnson WE, Campbell JD (2019) scruff: an R/ Bioconductor package for preprocessing single-cell RNA-sequencing data. BMC Bioinformatics 20:222.

Xie JY, Herman DS, Stiller C-O, Gardell LR, Ossipov MH, Lai J, Porreca F, Vanderah TW (2005) Cholecystokinin in the rostral ventromedial medulla mediates opioid-induced hyperalgesia and antinociceptive tolerance. J Neurosci 25:409-416.

Yazdani N, Parker CC, Shen Y, Reed ER, Guido MA, Kole LA, Kirkpatrick SL, Lim JE, Sokoloff G, Cheng R, Johnson WE, Palmer AA, Bryant CD (2015) Hnrnph1 is a quantitative trait gene for methamphetamine sensitivity. PLoS Genet 11:e1005713.
Zhang GH, Sweitzer SM (2008) Neonatal morphine enhances nociception and decreases analgesia in young rats. Brain Res 1199:82-90.

Zhang P, Moye LS, Southey BR, Dripps I, Sweedler JV, Pradhan A, Rodriguez-Zas SL (2019) Opioid-induced hyperalgesia is associated with dysregulation of circadian rhythm and adaptive immune pathways in the mouse trigeminal ganglia and nucleus accumbens. Mol Neurobiol 56:7929-7949.

Zhang Y, Donica CL, Standifer KM (2012) Sex differences in the Nociceptin/Orphanin FQ system in rat spinal cord following chronic morphine treatment. Neuropharmacology 63:427-433.

Zissen MH, Zhang G, Kendig JJ, Sweitzer SM (2006) Acute and chronic morphine alters formalin pain in neonatal rats. Neurosci Lett 400:154-157.

Zissen MH, Zhang G, McKelvy A, Propst JT, Kendig JJ, Sweitzer SM (2007) Tolerance, opioid-induced allodynia and withdrawal associated allodynia in infant and young rats. Neuroscience 144:247262. 